\title{
Reviewing Martian Atmospheric Noble Gas Measurements: From Martian Meteorites to Mars Missions
}

\author{
Thomas Smith ${ }^{1, *} \mathbb{C}$, P. M. Ranjith ${ }^{1}$, Huaiyu He ${ }^{1,2,3, *}$ and Rixiang Zhu ${ }^{1,2,3}$ \\ 1 State Key Laboratory of Lithospheric Evolution, Institute of Geology and Geophysics, \\ Chinese Academy of Sciences, 19 Beitucheng Western Road, Box 9825, Beijing 100029, China; \\ ranjith@mail.iggcas.ac.cn (P.M.R.); rxzhu@mail.iggcas.ac.cn (R.Z.) \\ 2 Institutions of Earth Science, Chinese Academy of Sciences, Beijing 100029, China \\ 3 College of Earth and Planetary Sciences, University of Chinese Academy of Sciences, Beijing 100049, China \\ * Correspondence: thomas.smith@mail.iggcas.ac.cn (T.S.); huaiyuhe@mail.iggcas.ac.cn (H.H.)
}

Received: 10 September 2020; Accepted: 4 November 2020; Published: 6 November 2020

\begin{abstract}
Martian meteorites are the only samples from Mars available for extensive studies in laboratories on Earth. Among the various unresolved science questions, the question of the Martian atmospheric composition, distribution, and evolution over geological time still is of high concern for the scientific community. Recent successful space missions to Mars have particularly strengthened our understanding of the loss of the primary Martian atmosphere. Noble gases are commonly used in geochemistry and cosmochemistry as tools to better unravel the properties or exchange mechanisms associated with different isotopic reservoirs in the Earth or in different planetary bodies. The relatively low abundance and chemical inertness of noble gases enable their distributions and, consequently, transfer mechanisms to be determined. In this review, we first summarize the various in situ and laboratory techniques on Mars and in Martian meteorites, respectively, for measuring noble gas abundances and isotopic ratios. In the second part, we concentrate on the results obtained by both in situ and laboratory measurements, their complementarity, and the implications for the Martian atmospheric dynamic evolution through the last billions of years. Here, we intend on demonstrating how the various efforts established the Mars-Martian meteorites connection and its significance to our understanding of the red planet.
\end{abstract}

Keywords: noble gases; Martian meteorites; mass spectrometry; space missions; atmospheric evolution

\section{Introduction and Backgrounds}

Noble gases, namely, helium, neon, argon, krypton, and xenon ( $\mathrm{He}, \mathrm{Ne}, \mathrm{Ar}, \mathrm{Kr}$, and $\mathrm{Xe}$ ), have been used as tools addressing a wide spectrum of scientific questions associated with terrestrial and extraterrestrial materials $[1,2]$. They are chemically inert, with very low chemical reactivity; their abundances in the atmospheres of terrestrial planets are mainly controlled by the outgassing of solid materials throughout their geological history [3]. In addition, their isotopic ratios can be modified by isotopic fractionation processes in relation to the evolution of planetary primary atmospheres during the early history of the Solar System. Therefore, noble gases are the best tools to investigate e.g., the evolution of atmospheric composition, and the surface-atmosphere volatile exchange [4]. Noble gases have been well studied on our planet and most of its reservoirs (atmosphere, hydrosphere, and mantle) [5-8], as well as in several planetary bodies of the Solar System. Relative noble gases abundances as well as their isotopic ratios provide constraints on the formation processes and the evolution of planetary bodies [9]. The abundances of noble gas isotopes in meteorites are controlled 
through different physical processes. One can distinguish between the so-called "in situ-produced noble gases" and "trapped" noble gases. Noble gases in meteorites can be produced in situ by spallation, radioactive decay, or fission reactions, defining cosmogenic, radiogenic, and fissiogenic noble gases, respectively (Table 1 ).

Table 1. Noble gases production in extraterrestrial material.

\begin{tabular}{|c|c|c|}
\hline Nuclide & Production Path & Main Target Elements \\
\hline${ }^{3} \mathrm{He}$ & Spallation & $\mathrm{O}, \mathrm{Mg}, \mathrm{Al}, \mathrm{Si}, \mathrm{Ca}, \mathrm{Fe}, \mathrm{Ni}$ \\
\hline${ }^{4} \mathrm{He}$ & $\begin{array}{c}\text { Radiogenic } \\
\text { Daughter of }{ }^{235,238} \mathrm{U} \text { and }{ }^{232} \mathrm{Th} \text { decay chains }\end{array}$ & $\mathrm{O}, \mathrm{Mg}, \mathrm{Al}, \mathrm{Si}, \mathrm{Ca}, \mathrm{Fe}, \mathrm{Ni}$ \\
\hline $20,21,22 \mathrm{Ne}$ & Spallation & $\mathrm{Mg}, \mathrm{Al}, \mathrm{Si}, \mathrm{Ca}, \mathrm{Fe}, \mathrm{Ni}$ \\
\hline${ }^{36} \mathrm{Ar}$ & Decay product of ${ }^{36} \mathrm{Cl}$ & $\mathrm{Cl}, \mathrm{Ca}, \mathrm{Ti}, \mathrm{Fe}, \mathrm{Ni}$ \\
\hline${ }^{38} \mathrm{Ar}$ & Spallation & $\mathrm{Cl}, \mathrm{Ca}, \mathrm{Ti}, \mathrm{Fe}, \mathrm{Ni}$ \\
\hline${ }^{40} \mathrm{Ar}$ & Radiogenic & Decay product of ${ }^{40} \mathrm{~K}$ \\
\hline${ }^{81} \mathrm{Kr}$ & Radioactive, $T_{1 / 2}=2.29 \times 10^{5}$ years & $\mathrm{Rb}, \mathrm{Sr}, \mathrm{Y}, \mathrm{Zr}$ \\
\hline $78,83,84,86 \mathrm{Kr}$ & Spallation & $\mathrm{Rb}, \mathrm{Sr}, \mathrm{Y}, \mathrm{Zr}$ \\
\hline${ }^{80,82} \mathrm{Kr}$ & $\begin{array}{c}\text { Spallation } \\
\text { Neutron capture of }{ }^{79,81} \mathrm{Br}\end{array}$ & $\mathrm{Br}, \mathrm{Rb}, \mathrm{Sr}, \mathrm{Y}, \mathrm{Zr}$ \\
\hline $124,126,128,130 \mathrm{Xe}$ & Spallation & $\mathrm{Te}, \mathrm{Ba}, \mathrm{La}, \mathrm{Ce}$ \\
\hline $129,131,132,134,126 \times \mathrm{Xe}$ & $\begin{array}{c}\text { Spontaneous, and induced fission on } \mathrm{U} \text { and } \\
\text { extinct }{ }^{244} \mathrm{Pu}\end{array}$ & $\mathrm{Te}, \mathrm{Ba}, \mathrm{La}, \mathrm{Ce}, \mathrm{U}$ \\
\hline${ }^{129} \mathrm{Xe}$ & $\begin{array}{c}\text { Radiogenic } \\
{ }^{129} \mathrm{Xe} \text { is the decay product of extinct }{ }^{129} \mathrm{I}\end{array}$ & $\mathrm{Te}, \mathrm{Ba}, \mathrm{La}, \mathrm{Ce}, \mathrm{U}$ \\
\hline
\end{tabular}

- First, the cosmogenic noble gases are produced by spallation reactions on specific target elements in the meteorites during their transfer from their parent body to Earth (Table 1). Cosmic rays are energetic particles mainly composed of protons and $\alpha$-particles, and minor amounts of heavy ions, and can be divided into Galactic Cosmic Rays (GCRs) and Solar Cosmic Rays (SCRs). Galactic Cosmic Rays are omnidirectional in space, most likely produced in supernovae, and are highly energetic. On the other hand, SCRs are produced by the Sun (solar flares and coronal mass ejections); their intensities decrease with increasing distance from the Sun. In meteorites, the signatures of ${ }^{3} \mathrm{He},{ }^{21} \mathrm{Ne}$, and ${ }^{38} \mathrm{Ar}$ mostly represent spallation reactions. These cosmogenic noble gases are not only produced in meteorites, but also on airless bodies (Moon, near-Earth objects, asteroids, etc.) and to some extent the surface of Mars, also exposed to GCR spallation reactions in rocks.

- Second, radiogenic and fissiogenic noble gases in rocks are produced by decay and fission of radionuclides, respectively. For example, radiogenic ${ }^{4} \mathrm{He}_{\text {rad }}$ is produced mainly from the decay of ${ }^{235} \mathrm{U},{ }^{238} \mathrm{U}$, and ${ }^{232} \mathrm{Th}$. Similarly, radiogenic ${ }^{40} \mathrm{Ar}_{\text {rad }}$ is produced by the decay of ${ }^{40} \mathrm{~K}\left(T_{1 / 2}=1.25 \mathrm{Ga}\right)$, whereas radiogenic ${ }^{129} \mathrm{Xe}_{\text {rad }}$ is mainly produced through the decay of short lived but now extinct ${ }^{129} \mathrm{I}\left(\mathrm{T}_{1 / 2}=15.7 \mathrm{Ma}\right)$. On the other hand, heavy isotopes of $\mathrm{Kr}$ and Xe are produced by the neutron induced fission of ${ }^{235} \mathrm{U}$ and through spontaneous fission of ${ }^{238} \mathrm{U}$ and the extinct ${ }^{244} \mathrm{Pu}$ [9].

In our Solar System, noble gases have received particular attention on

- the Moon, through the unmanned and manned missions, rocks returned from the Moon, and in lunar meteorites [10,11];

- Jupiter, thanks to the Galileo Probe Mass Spectrometer (GPMS), which investigated the planet in 1995 and revealed the composition of the Jovian atmosphere [12,13];

- the comet 67P Churyumov-Gerasimenko with ROSINA (Rosetta Orbiter Spectrometer for Ion and Neutral Analysis) onboard the Rosetta mission [14-17]; and

- Mars, where during the recent decades, four space missions have measured atmospheric composition in the Martian atmosphere, including the noble gas abundances as well as their isotopic ratios by mass spectrometry or EUV spectroscopy: the Viking suites of missions (1976-1982), 
the Curiosity rover on the Mars Science Laboratory (MSL) (2012), the Mars Atmosphere and Volatile Evolution (MAVEN, 2014), or the Mars Orbiter Mission (MOM, 2014). Thus, the Viking mission in 1976 provided the first elemental and isotopic abundances of the volatiles in the Martian atmosphere [18-20], etc.

On one hand, the noble gas abundances and their isotopic ratios in planetary atmospheres can be addressed by in situ measurements made by entry probes, because of the absence of radio signals in the planetary atmospheres [21]. Precise measurements are therefore necessary and represent a primary focus in planetary atmosphere exploration.

On the other hand, in addition to space missions, the natural history of Mars can be also unraveled from Martian meteorites. The Martian meteorites were first identified after the analysis of the Antarctic meteorite Elephant Moraine (EETA) 79001 [22] (Figure 1a). This meteorite clearly shows the presence of glasses which probably formed by an impact on Mars that ejected EETA 79001. Similar features are observed in the Martian meteorite Tissint (Figure 1b). It is believed that these glasses encapsulated the composition of the Martian atmosphere at the time of the impact. Therefore, trapped noble gases ( $\mathrm{Ne}, \mathrm{Ar}, \mathrm{Kr}$, and $\mathrm{Xe}$ ), as well as nitrogen $\mathrm{N}_{2}$ and $\mathrm{CO}_{2}$ abundances in black glasses separated from EETA 79001 showed a 1:1 correlation (on a log-log plot) with the volume abundances measured for Martian atmosphere by the Viking mission (Figure 2) [22].

In addition, noble gas isotopic ratios such as ${ }^{40} \mathrm{Ar} /{ }^{36} \mathrm{Ar}$ and ${ }^{129} \mathrm{Xe} /{ }^{132} \mathrm{Xe}$ in the glasses of EETA 79001 are consistent with the values from Viking measurements $[23,24]$. Thus, noble gas abundances and their isotopic ratios provided the determining link between the surface of Mars and suggested fragments of Mars in the form of Martian meteorites. Since the study of EETA 79001, there are 277 records for Martian meteorites in the Meteoritical Bulletin database as of 8 August 2020 (https://www.lpi.usra.edu/meteor/metbull.php). However, for some records, there is more than one officially recognized name, because of naturally paired specimens or broken pieces of the same original single stone (several meteorites are defined as paired when they were ejected from the same impact event). The actual number of unpaired Martian meteorites is probably slightly less than 149 [25], as pairing relationships has to be confirmed through combination of noble gases/radionuclide measurements to determine their cosmic ray exposure ages (the time meteorites have been irradiated by cosmic-rays in space).

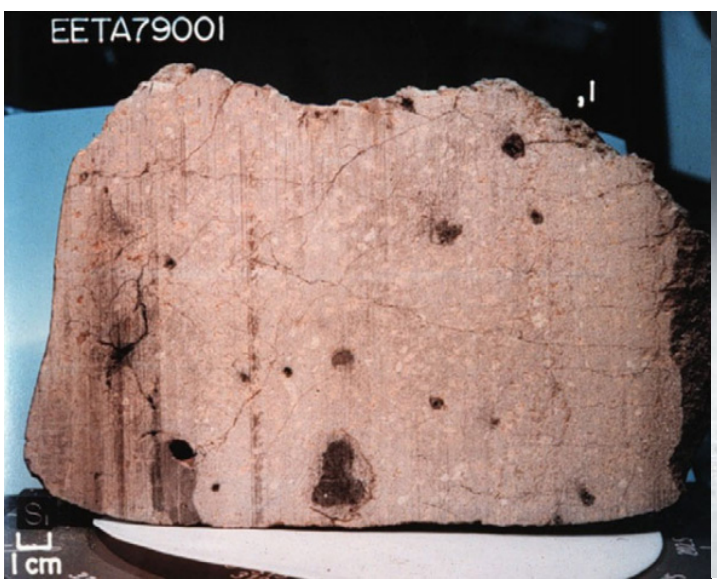

(a)

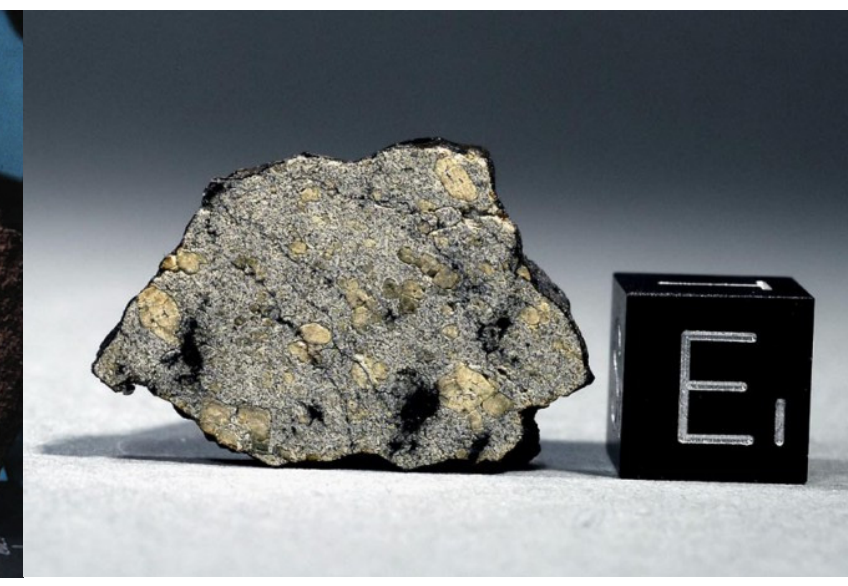

(b)

Figure 1. (a) The Martian meteorite Elephant Moraine (EETA) 79001 and the presence of black glass which contains trapped Martian atmosphere. Credit from NASA. (b) A fragment of Tissint meteorite with shock-produced glass pockets (black), photo credit Meteor-Center (scale is represented by the 1 inch scale cube). 


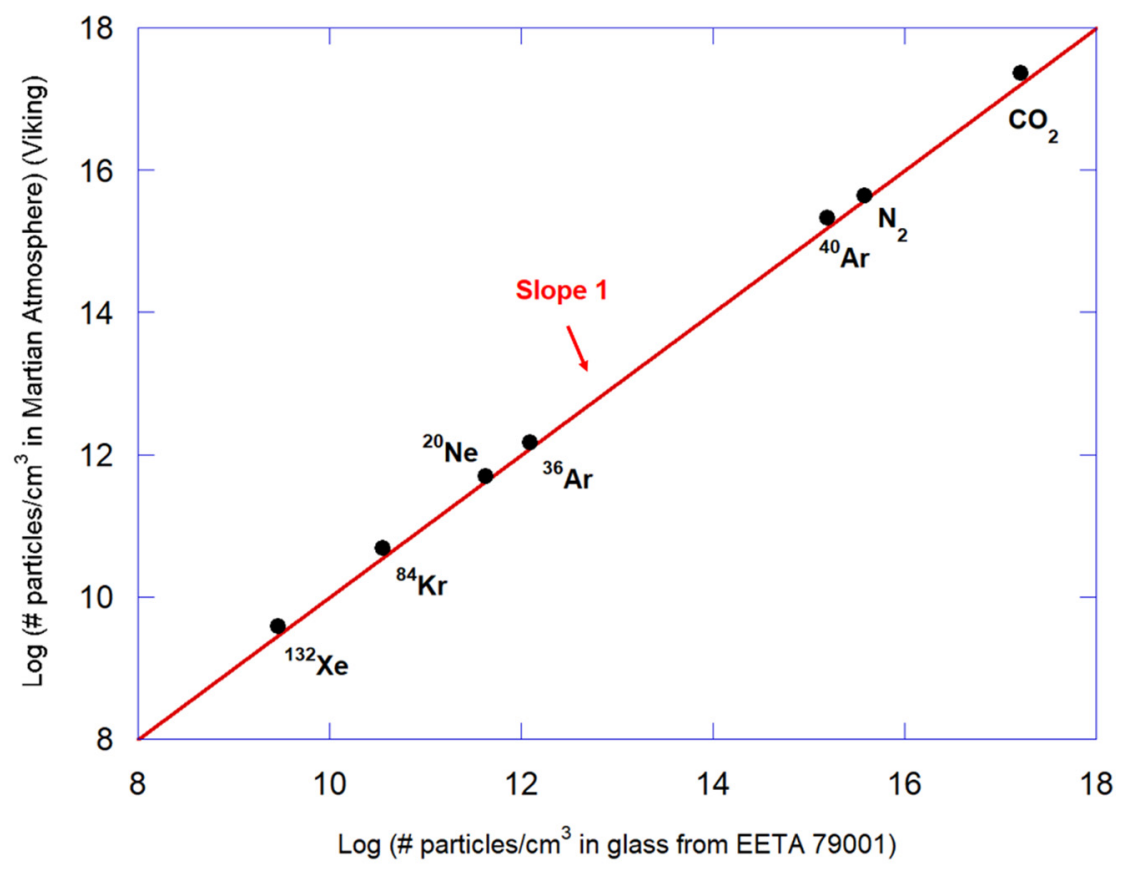

Figure 2. Log-log plot of the volume abundance of gases (number of particles per cubic centimeter) measured by Viking in the Martian atmosphere and in EETA 79001 glass [22].

Martian meteorites are typically classified into Shergottites-Nakhlites-Chassignites (SNCs) by their similar petrographic and mineralogical features; however, there exist several unique meteorites such as ALH 84001 or Northwest Africa (NWA) 7034 [25]. Although most of the Martian meteorites available for research today are finds, especially from the desert of Northwest Africa (NWA), there are five famous recorded falls of Martian meteorites: Chassigny (fell in France in 1815), Shergotty (fell in India in 1865), Nakhla (fell in Egypt in 1911), Zagami (fell in Nigeria in 1962), and the most recent fall, Tissint (fell in Morocco in 2011).

Nakhlites are a group of clinopyroxenites, which probably crystallized within the same igneous cumulate pile [26]. There are so far three Chassignites (Chassigny, NWA 2737, and NWA 8694), which contain olivine as major phase and pyroxene, chromite, and feldspar as minor phases. Olivine contains fluid inclusions which may host noble gases associated with the fluids in the interior of Mars, though noble gases from these inclusions have not been studied separately [9]. However, detailed studies of $\mathrm{Kr}$ and Xe isotopes point towards Chassigny as a sample of Mars interior [27]. ALH 84001 is an orthopyroxene cumulate with some minor phases such as chromite, maskelynite and carbonate [26]. NWA 7034 and its paired specimens (NWA 7475, 7533, 7906, 7907, 8114) are the only regolith breccias in the Martian meteorite collection [28]. Almost $80 \%$ of Martian meteorites are shergottites, which are further divided into subgroups such as basaltic, lherzolitic, olivine-orthopyroxene and olivine-phyric, based on their mineral composition and texture.

In Martian meteorites, the "trapped" noble gases are mainly inherited from the Martian atmosphere/interior. In addition, terrestrial atmospheric noble gases can be trapped or incorporated into the meteorites through processes like impact, or terrestrial alteration during the Martian meteorite residence time on Earth. The isotopic noble gas signature in Martian meteorites usually consists of a mixture of both in situ and trapped noble gases.

As mentioned above, trapped noble gases in Martian meteorites serve as benchmarks in identifying the origin of Martian meteorites and in the study of the Martian atmosphere or interior [22-29]. In attempting to avoid as much as possible the contribution of cosmogenic noble gases, the "best" Martian meteorite samples for studying the Martian atmospheric composition are the meteorites with a low exposure ages (and therefore with a low cosmogenic noble gas contribution). 
Both elemental abundances and isotopic ratios of a single noble gas are likely to be modified due to the escape of a primary atmosphere in the early history of the Solar System [30]. Physical processes leading gas to escape to space preferentially remove the lighter isotopes, thereby leaving the remaining atmosphere enriched in the heavier. These processes therefore lead to the progressive isotopic fractionation of planetary atmospheres, with heavy isotopic enrichments being consistent with atmospheric loss to space. Such fractionation processes in noble gas isotopic ratios and abundances were identified by, e.g., Viking or Curiosity. As an example, the Curiosity Ar isotopic measurements revealed fractionated ${ }^{36} \mathrm{Ar} /{ }^{38} \mathrm{Ar}$ ratios [31] compared to Solar ${ }^{36} \mathrm{Ar} /{ }^{38} \mathrm{Ar}$ ratio [2], and assuming that Mars originally condensed with this value. It therefore suggests a loss of Ar to space by pickup-ion sputtering, preferentially removing lighter atoms, i.e., ${ }^{36} \mathrm{Ar}$ [32]. In addition, Xe heavy isotopic enrichments observed in the Martian atmosphere by Viking and Curiosity can be explained by a preferential loss of light Xe isotopes to space by hydrodynamic escape [33-35]. Extreme UV exposure to the early Martian atmosphere by the young evolving Sun can account for the dissipation of primary planetary atmospheres around low-gravity planetary bodies [30-35].

In this review, we evoke the case for determining the Ne isotopic composition of the Martian atmosphere, which has not yet been measured by any of the Mars missions, and still under debate after measurement in a series of Martian meteorites [36-38]. Indeed, Martian neon isotopic signatures are challenging to characterize since the cosmogenic production dominates in the case of Ne isotopes. Therefore, searching for trapped Ne isotopes calls for more measurements in the laboratory. Indeed, the study of trapped noble gases in Martian meteorites enables a higher precision in the elemental and isotopic ratio measurements when compared to in situ measurements by spacecrafts which suffer from limitations (lower precisions, limitation to measurements of high abundance isotopes, etc.).

In this short review, we discuss how the noble gas composition of Mars atmosphere was investigated in the past decades, based on both space missions and on laboratory measurements of Martian meteorites [22-39]. We first review the technical aspects for the measurement of noble gases at Mars and in Martian meteorites. Then, we summarize key noble gas data and highlight the complementarity between in situ Mars and Martian meteorite measurements establishing the Mars-Martian meteorite connection. The implications of these noble gas data on the Martian atmospheric composition and evolution, with a more particular emphasis on the atmospheric loss processes through geological time, are then addressed.

\section{Noble Gases in Martian Atmosphere and In Martian Meteorites Measured In Situ or In the Laboratory: Technical Aspects}

\subsection{The Atmospheric Noble Gas Composition of Mars: The Latest Significant Missions}

Over the last five decades, four space missions to Mars measured the composition of the Martian atmosphere, and particularly noble gas abundances and isotopic compositions: Viking, Curiosity, the Mars Atmosphere and Volatile Evolution (MAVEN), and the Mars Orbiter Mission (MOM). Here, we provide a technical summary of the noble gas measurements of the Martian atmosphere in situ and in laboratories on Earth. The results will be discussed in Section 3.

\subsubsection{The Viking Project (1976-1982)}

NASA's Viking Project was the first U.S. mission to land a spacecraft safely on the surface of Mars. The Viking 1 lander landed on the western slope of Chryse Planitia on 19 June 1976, while the Viking 2 lander touched down at Utopia Planitia on 3 September 1976, performing the very first geochemical exploration of Mars. Measurement of the Martian atmospheric gas composition was made by mass spectrometers onboard the Viking landers (Table 2) [18-20]. The abundances of $\mathrm{CO}_{2}$; $\mathrm{H}_{2} \mathrm{O} ; \mathrm{N}_{2} ; \mathrm{O}_{2}$; the noble gases; as well as the isotopic ratios of hydrogen, carbon, oxygen, nitrogen, argon, krypton, and xenon were measured. The mass spectrometer onboard the Viking molecular 
analysis experiment had a high sensitivity, a high mass range, and a high resolution which facilitated a better characterization of minor atmospheric components. Such characteristics were suitable for the measurement of the noble gas abundances in the Martian atmosphere. Thus, two methods were adopted for the atmospheric analyses; the atmosphere was either directly inlet into the mass spectrometer for the measurement, or gas scrubbers were used to reduce the partial pressures of species such as $\mathrm{CO}$ and $\mathrm{CO}_{2}$, which otherwise could compromise the measurement. In the latter case, a mixture of $\mathrm{Ag}_{2} \mathrm{O}$ and $\mathrm{LiOH}$ was used as an absorber. After the elimination of $99 \%$ of the $\mathrm{CO}_{2}$, the concentrations of the noble gases were increased by successively repeating the ingestion and purification procedures. By these successive enrichments and by increasing the electron multiplier gain, $\mathrm{Kr}$ and Xe peaks were observed. A combination of 15 cycles measured with the electron multiplier after chemical purification lead to increase the signal-to-noise-ratio by a factor of 5.3 over the nominal value [18-20]. A lower ionization energy was also used to reduce the interference caused by the double ionized species, particularly problematic for the Ne measurements (i.e., ${ }^{40} \mathrm{Ar}^{++}$for ${ }^{20} \mathrm{Ne}$ and ${ }^{44} \mathrm{CO}_{2}{ }^{++}$for ${ }^{22} \mathrm{Ne}$ ). By using the chemical scrubbers to reduce the $\mathrm{CO}_{2}$ partial pressure, the observed contribution of interfering $\mathrm{CO}_{2}$ at $m / e=22$ was less than one third.

Table 2. Composition of the Martian lower atmosphere [18].

\begin{tabular}{cc}
\hline Gas & Abundance \\
\hline $\mathrm{CO}_{2}$ & $95.32 \%$ \\
$\mathrm{~N}_{2}$ & $2.7 \%$ \\
$\mathrm{Ar}$ & $1.6 \%$ \\
$\mathrm{O}_{2}$ & $0.13 \%$ \\
$\mathrm{CO}$ & $0.07 \%$ \\
$\mathrm{H}_{2} \mathrm{O}$ & $0.03 \%$ \\
$\mathrm{Ne}$ & $2.5 \mathrm{ppm}$ \\
$\mathrm{Kr}$ & $0.3 \mathrm{ppm}$ \\
$\mathrm{Xe}$ & $0.08 \mathrm{ppm}$ \\
$\mathrm{O}_{3}$ & $0.03 \mathrm{ppm}$ \\
\hline
\end{tabular}

\subsubsection{The Mars Science Laboratory Mission (2012)}

The Mars Science Laboratory (MSL) onboard the Curiosity rover landed in Gale Crater on 5 August 2012. MSL is equipped with a suite of scientific instruments including the Sample Analysis at Mars (SAM). The SAM suite onboard the Curiosity rover has three instruments dedicated to the study of gas and/or solid samples, including a quadrupole mass spectrometer (QMS), a tunable laser spectrometer (TLS), and a 6-column gas chromatograph (GC) system [4-40]. The combination of both QMS and TLS enables multiple and high-precision composition measurements throughout the mission.

Prior to any measurement, both QMS and TLS were evacuated using turbomolecular pumps. The Martian atmospheric samples were then inlet into a pre-evacuated (at $50^{\circ} \mathrm{C}$ ) manifold. Chemical scrubbers and zeolites helped reduce the partial pressure of active gases (e.g., $\mathrm{CO}_{2}$ and $\mathrm{H}_{2} \mathrm{O}$ ) by more than $95 \%$, which would otherwise compromise any measurements. The post-purification gas consists of a gas mixture enriched in $\mathrm{N}_{2}, \mathrm{Ar}, \mathrm{Kr}$, and $\mathrm{Xe}$. The gas is then channeled through a cooled hydrocarbon trap which traps $\mathrm{Xe}$, whereas other gases passed through.

The ingestion and purification of gases are repeated several times until reaching a noble gas density sufficient enough to achieve high signal over background ratios. Background measurements are performed when the QMS is opened to the evacuated manifold. The Martian atmosphere is subsequently inlet for $\sim 30 \mathrm{~s}$ to a portion of the manifold. A small fraction of this gas is finally inlet into the QMS in a dynamic sampling mode.

\subsubsection{MAVEN (2014)}

The main aim of the Mars Atmosphere and Volatile Evolution (MAVEN) mission was to study the Martian atmosphere, the geological evolution and potential habitability of the planet [32-42]. 
The MAVEN mission objectives particularly aimed at evaluating the amount of atmospheric gas which has been lost to space over geological time through, among others, the ratio of ${ }^{38} \mathrm{Ar} /{ }^{36} \mathrm{Ar}$. Argon can be removed from the Martian atmosphere by only solar-wind-induced sputtering (pick-up ion sputtering) [32]: the higher scale height of ${ }^{36} \mathrm{Ar}$ relative to ${ }^{38} \mathrm{Ar}$ implies that the lighter isotope is more abundant in the upper atmosphere, thus proportionally more ${ }^{36} \mathrm{Ar}$ is removed by sputtering. Therefore, measuring precisely the ${ }^{38} \mathrm{Ar} /{ }^{36} \mathrm{Ar}$ ratio is of great significance as it can give information to determine the sputtering loss of other atoms and molecules.

The composition, structure, and variability of the upper atmosphere of Mars were characterized by the Neutral Gas and Ion Mass Spectrometer (NGIMS) onboard the MAVEN mission [42]. The NGIMS instrument, a direct heritage from e.g., Galileo GPMS or Pioneer Venus ONMS, consists of a quadrupole mass spectrometer with open and closed sources, for neutral and ions, and for non-reactive neutrals (i.e., $\mathrm{Ar}, \mathrm{He}, \mathrm{CO}_{2}, \mathrm{~N}_{2}$, and $\mathrm{CO}$ ), respectively. Its design enables neutral masses ranging from $\sim 2$ amu to $\sim 150 \mathrm{amu}$ to be measured. The incoming signal is reduced by a factor of $\sim 10$ or $\sim 100$, enabling the QMS to detect densities of gas at much higher concentrations than in normal operating mode. This is particularly suitable for the measurement of high concentrations of $\mathrm{Ar}, \mathrm{CO}_{2}$, or $\mathrm{CO}$, and $\mathrm{O}$ in the Martian atmosphere, which would normally saturate the detector at nominal attenuation. See Mahaffy et al., 2015 for further details about the NGIMS instrument and characteristics [42].

\subsubsection{MENCA Onboard MOM (2014)}

India's first mission to Mars, Mars Orbiter Mission (MOM), was inserted into the Martian orbit on 24 September 2014. The Mars Exospheric Neutral Composition Analyzer (MENCA) is one of the science instruments onboard the MOM mission; it was equipped with a quadrupole mass spectrometer which is capable of total pressure measurements, thanks to a Bayard Alpert gauge $[43,44]$. Similar to the NGIMS in MAVEN mission, the main objective of MENCA was to understand the escape of the Martian atmosphere over geological time; in addition, ${ }^{40} \mathrm{Ar}$ being one of the minor constituents of the Martian atmosphere, its variability has direct implications regarding atmospheric evolution processes on Mars. The MENCA was equipped with two detectors, a Faraday cup, and a channel electron multiplier, in a dynamic range of $10^{10}$. The quadrupole mass spectrometer was therefore also sensitive enough to measure the tenuous exosphere of Mars. MENCA measured the relative abundances of neutral constituents in the mass range of 1 to 300 atomic mass units [43,44].

The goals and achievements of these missions to Mars, in terms of noble gas elemental abundance and isotopic ratio measurements, are summarized in Table 3.

\subsection{Noble Gas Mass Spectrometry Analyses in Laboratory}

A noble gas mass spectrometer is mostly used to measure noble gases (from He to Xe). Noble gas mass spectrometry determines accurate measurements of noble gas concentrations and isotopic ratios of various terrestrial and extraterrestrial materials (cf. introduction and references therein). In addition, the study of Martian meteorites provides even higher precision in the noble gas elemental abundances and isotopic ratios compared to spacecraft.

Noble gases are extracted from meteorite samples through heating (pyrolysis or combustion) in a single step at a temperature high enough to release all noble gases at once or by incremental heating in discrete temperature steps [45]. Based on the science question and the type of the meteorite, one can choose the method of heating. General heating methods involve resistance furnace heating and laser ablation. In some special types of meteorites, gas extraction can be done through vacuum crushing and combustion coupled with pyrolysis heating. Here, we will briefly describe and explain the state-of-the-art technical aspects of noble gas mass spectrometry on meteorite samples. In some cases, noble gases and nitrogen have been measured simultaneously. In addition, the Open University, UK, is, so far, the unique facility capable of measuring carbon, nitrogen, and noble gas isotopes simultaneously. 
Table 3. List, goals, and achievements of the latest missions to Mars for the measurement of noble gas elemental abundances and isotopic ratios.

\begin{tabular}{|c|c|c|c|}
\hline Mission & Goals & Payloads & Achievements \\
\hline Viking & $\begin{array}{l}\text {-Detect and identify } \\
\text { organic compounds } \\
\text {-Determine the composition } \\
\text { of the lower atmosphere }\end{array}$ & $\begin{array}{l}\text { Mass spectrometer } \\
\text { coupled with } \\
\text { gas chromatograph }\end{array}$ & $\begin{array}{c}\text {-Atmospheric elemental } \\
\text { abundances, } \\
\text { including noble gases }\end{array}$ \\
\hline Curiosity & $\begin{array}{l}\text {-Understand the potential of } \\
\text { the present or past Martian } \\
\text { environments to support life } \\
\text {-Chemical and isotopic } \\
\text { composition of } \\
\text { the atmosphere }\end{array}$ & $\begin{array}{l}\text { Sample Analysis at Mars } \\
\text { (SAM): quadrupole mass } \\
\text { spectrometer, } \\
\text { tunable laser } \\
\text { spectrometer, } \\
\text { gas chromatograph }\end{array}$ & $\begin{array}{l}\text {-Measurements of all of } \\
\text { the stable isotopes of the } \\
\text { heavy noble gases in the } \\
\text { Martian atmosphere }\end{array}$ \\
\hline MAVEN & $\begin{array}{l}\text {-Study the Martian } \\
\text { atmosphere, and the } \\
\text { geological evolution and } \\
\text { potential habitability of } \\
\text { the planet } \\
\text {-Evaluate the amount of } \\
\text { atmospheric gas which has } \\
\text { been lost to space over } \\
\text { geological time }\end{array}$ & $\begin{array}{l}\text { Neutral Gas and Ion } \\
\text { Mass Spectrometer } \\
\text { (NGIMS), a quadrupole } \\
\text { mass spectrometer }\end{array}$ & $\begin{array}{l}\text {-Characterization of the } \\
\text { Martian upper } \\
\text { atmospheric structure } \\
\text {-Fractionation of argon }\end{array}$ \\
\hline MOM & $\begin{array}{l}\text { Understand the escape of the } \\
\text { Martian atmosphere over } \\
\text { geological time }\end{array}$ & $\begin{array}{l}\text { Mars Exospheric Neutral } \\
\text { Composition Analyser } \\
\text { (MENCA), a quadrupole } \\
\text { mass spectrometer }\end{array}$ & $\begin{array}{c}\text {-Exospheric } \\
\text { composition of Mars } \\
\text {-Altitude profiles of } \\
{ }^{40} \mathrm{Ar} \text { in the } \\
\text { Martian exosphere }\end{array}$ \\
\hline
\end{tabular}

\subsubsection{Sample Preparation}

Prior to any noble gas measurement of meteorite specimens, samples are first cleaned with ethanol in an ultrasonic bath, dried, weighed, and then loaded into a sample chamber connected to a noble gas extraction and purification line. Typically, after any sample loading, the whole system (sample chamber volume and extraction and purification line) is baked and evacuated for $\sim 1-3$ days at $\sim 120^{\circ} \mathrm{C}$ in order to remove adsorbed atmospheric gases. In the case of Martian meteorites, the sample mass can range between few $\mathrm{mg}$ to hundreds of $\mathrm{mg}$, depending upon the method of gas extraction.

The best samples to search for Martian atmospheric signatures are shock-induced glasses separated from, e.g., the shergottites. For example, signatures of Martian atmosphere, based on $\mathrm{N}_{2}$, Ar and Xe isotopes, were determined in separated millimeter sized pockets of shock-melted glass in the meteorite Zagami [29]. In addition, noble gases were measured in glass samples from the latest Martian meteorite fall, Tissint [46,47]. In all of these studies, glass samples were prepared through hand picking. When a complete separation is not possible, glass separates with some matrix minerals were also used for noble gas measurements.

\subsubsection{Pyrolysis: Total Fusion or Stepwise Heating}

As mentioned above, pyrolysis is done either in a single step or in multi-steps, based on the type of sample and the scientific objectives. If the sample size is restricted to a few $\mathrm{mg}$ (e.g., less than $10 \mathrm{mg}$ ), laser heating can be adopted for total fusion. However, in the cases of relatively large samples (tens of $\mathrm{mg}$ to a few grams), total extraction can be achieved by heating in a crucible made of a metal with high melting temperature (Ta, Mo, or W) [45]. Crucibles and samples are heated by radiofrequency induction, by applying a current through a resistance, or by electron bombardment. Single grain analysis is usually done by laser ablation. In addition, lower instrumental blanks used in furnace heating are an advantage for laser heating. In some cases, noble gases are extracted in different steps, due to some specific scientific objectives such as (1) the selective identification of a particular component of interest, 
(2) to decipher spatial distribution of noble gas components in mineral grains, (3) to infer noble gas diffusion coefficients, and (4) to avoid terrestrial contamination in some meteorites [45]. After the samples are loaded in the preparation system, and before sample measurements, calibrations are regularly performed using standard gases of known noble gas isotopic composition or air. Instrumental mass discriminations are as well derived from calibration measurements. Instrumental blanks are repeatedly measured, usually before and after each sample, using the same extraction procedure as for the samples. Noble gases are extracted by heating the samples in either a single extraction step or in stepwise heating for a duration of several minutes to $\sim 30 \mathrm{~min}$. The released gases are subsequently cleaned from all reactive gases which would compromise the measurements such as $\mathrm{CO}_{2}, \mathrm{H}_{2} \mathrm{O}$, or hydrocarbons, etc. using a series of getters, operating at various temperatures [48,49].

\subsubsection{Combustion}

In order to measure noble gases released during progressive outgassing of the mineral host phases, differential combustion in molecular oxygen is usually adopted as an extraction method for Martian meteorites and carbonaceous chondrites [29-50]. Stepped combustion helps to resolve different carbon bearing components on the basis of thermal stability under oxygen. This method is usually adopted when noble gases are measured simultaneously with $\mathrm{C}$ and $\mathrm{N}$ isotopes. As volatile compounds such as atmospheric adsorbed gases or organic species are released at low temperature $\left(\sim 300^{\circ} \mathrm{C}\right)$, a combustion at a low temperature helps to identify the composition of trapped noble gases. For example, in such a study, N, Ar, and Xe were released from separated glass samples from the Zagami meteorite, through combustion in pure $\mathrm{O}_{2}$ at a pressure of 5 torr (up to $800^{\circ} \mathrm{C}$ ), followed by pyrolysis (up to $1500^{\circ} \mathrm{C}$ ) [29].

\subsubsection{Crushing Technique}

In order to separate trapped and cosmogenic noble gas components, vacuum crushing is an efficient method. It was demonstrated for example in Martian meteorites [51], especially to have access to the trapped gases implanted from the Martian atmosphere, which usually reside in the glass vesicles of the meteorites.

However, prolonged crushing might induce heating, which may also release matrix sited cosmogenic He as observed in some previous studies [52]. Nevertheless, ${ }^{3} \mathrm{He}$ is only lost during hot conditions, with temperatures $>300{ }^{\circ} \mathrm{C}$ [52]. Noble gases released using this technique appeared to be quite different from the Martian atmospheric signature. In particular, $\mathrm{Kr}$ and $\mathrm{Xe}$ isotopic signatures are indistinguishable from terrestrial and/or Martian atmosphere [53]. Vacuum crushing is extensively used in, e.g., terrestrial mantle materials when searching for noble gases trapped in fluid inclusions, where usually a few grams of sample are crushed at a pressure of 1500-2000 psi ( $1 \mathrm{psi}=51.715$ torr) [48-54]. However, in the cases of Martian meteorite samples, the sample masses are lower-usually 100-200 mg [36]. Note that after crushing, the samples can be recovered and subsequently loaded into a furnace or in a laser chamber for further stepwise heating combustion or pyrolysis [36].

\subsubsection{Separation and Purification}

After gas extraction (e.g., by pyrolysis, combustion, or crushing), all active gases have to be removed before introducing noble gases into the mass spectrometer. The usual method for removing active gases requires getters, made of chemically reactive metals or metal alloys such as $\mathrm{ZrAl}$ or ZrTi [45]. In order to have a maximum surface area, these materials are often porous.

Purification procedures may vary slightly between laboratories depending on the types of materials used in various parts of the preparation system. From the purified gas mixture, the He-Ne fraction is separated from the Ar-Kr-Xe fraction using an activated charcoal held at the temperature of liquid nitrogen $\left(\mathrm{LN}_{2}\right)$ for $20 \mathrm{~min}$. Subsequently, the Ne fraction is separated from He by using a cryogenic cold trap held at $35 \mathrm{~K}$ for $\sim 10 \mathrm{~min}$ [48]. Generally, the trapping medium is charcoal, but note that 
the trapping temperature may vary depending on the medium. After having trapped $\mathrm{Ne}$, a fraction of the He gas is then inlet into the mass spectrometer for measurement. After He measurements, the Ne fraction is released at $80 \mathrm{~K}$ for $\sim 30 \mathrm{~min}$ [48], and inlet into the mass spectrometer for subsequent measurement. During Ne measurements, the remaining background gases, especially ${ }^{40} \mathrm{Ar}^{++}$and $\mathrm{CO}_{2}{ }^{++}$interfering at $m / e=20$ and $m / e=22$, respectively, are further reduced using a charcoal trap held at $\mathrm{LN}_{2}$ temperature, adjacent to the mass spectrometer source. At the same time, all heavy noble gases are released (here a mixture of $\mathrm{Ar}, \mathrm{Kr}$, and $\mathrm{Xe}$ ) from a cold trap with active charcoal at $\sim 420-480 \mathrm{~K}$. The Ar fraction is then usually separated from the $\mathrm{Kr}$ and Xe fractions using a cold trap (charcoal or in some cases a cryogenic trap) at a temperature on the sorption-desorption characteristics of the considered trap. It varies between $150 \mathrm{~K}$ and $155 \mathrm{~K}$ for cold trap with active charcoal [55] and around $85 \mathrm{~K}$ for nude cryogenic traps [56], and by doing so, only $\mathrm{Kr}$ and Xe remain trapped; all of the Ar will remain as a gas and can be further trapped and subsequently measured. The $\mathrm{Kr}$ fraction can then be separated from the Xe fraction at the given temperature ( $198 \mathrm{~K}$ for cold trap with active charcoal, and around $~ 95-100 \mathrm{~K}$ for nude cryogenic traps), and subsequently inlet into the mass spectrometer. Finally, after $\mathrm{Kr}$ measurement, the remaining Xe is released at $\sim 420-480 \mathrm{~K}$ for $\sim 20 \mathrm{~min}$ and is further inlet into the mass spectrometer. However, in most cases, (Ar) $\mathrm{Kr}$ and $\mathrm{Xe}$ are not separated and measured consecutively, in order to avoid some possible isotopic fractionation processes as well as separation loss [57,58]. After the first measurement, second extractions at slightly higher temperatures are systematically performed in order to ensure the good first extraction rates. Additional extractions are performed as long as the gas amount from the successive extractions remains significant.

\section{The Noble Gas Composition of Martian Atmosphere and Interior}

Here we compare the isotopic ratio of trapped noble gases ( $\mathrm{Ne}$, $\mathrm{Ar}$, and $\mathrm{Xe}$ ) from in situ Viking and Curiosity measurements with laboratory analysis of Martian meteorites (Figure 3, Table 4).

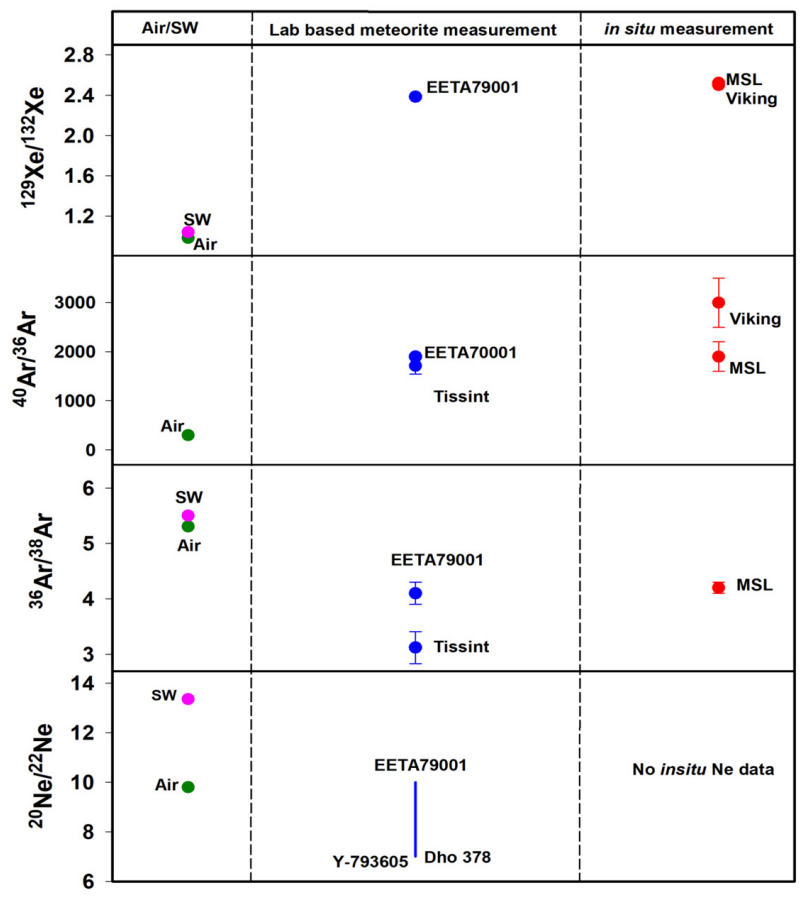

Figure 3. Neon, argon, and xenon isotopic composition in the solar wind (SW), Earth atmosphere, Martian meteorite measurements, and in situ measurement on Mars. In the figure, we report ${ }^{20} \mathrm{Ne} /{ }^{22} \mathrm{Ne}$ values in SW [60] and in Martian meteorites [35-62]. In Martian meteorites, the ${ }^{20} \mathrm{Ne} /{ }^{22} \mathrm{Ne}$ ratios are in the range 7.0 to 10.6 [38]. The isotopic ratio in meteorites are ${ }^{36} \mathrm{Ar} /{ }^{38} \mathrm{Ar}=3.5-4.6$ [62], ${ }^{40} \mathrm{Ar} /{ }^{36} \mathrm{Ar}=1714$ \pm 170 [46] and $2050 \pm 70[63]{ }^{129} \mathrm{Xe} /{ }^{132} \mathrm{Xe}=2.384 \pm 0.020$ [64]. For the in situ measurements ${ }^{36} \mathrm{Ar} /{ }^{38} \mathrm{Ar}$ $=4.2 \pm 0.1[31],{ }^{40} \mathrm{Ar} /{ }^{36} \mathrm{Ar}=1900 \pm 300(\mathrm{MSL})$ [40]; $3000 \pm 500$ (Viking) [65], ${ }^{129} \mathrm{Xe} /{ }^{132} \mathrm{Xe}=2.522$ [41]. 
Table 4. The noble gas isotopic ratios as measured by the Viking [20] and Curiosity missions [31-41].

\begin{tabular}{ccc}
\hline Isotopic Ratios & Viking & Curiosity \\
\hline${ }^{20} \mathrm{Ne} /{ }^{22} \mathrm{Ne}$ & $10 \pm 3$ & - \\
${ }^{36} \mathrm{Ar} /{ }^{38} \mathrm{Ar}$ & $5.5 \pm 1.5$ & $4.2 \pm 0.1$ \\
${ }^{40} \mathrm{Ar} /{ }^{36} \mathrm{Ar}$ & $3000 \pm 500$ & $1900 \pm 300$ \\
${ }^{84} \mathrm{Kr} / 86 \mathrm{Kr}$ & - & $3.269 \pm 0.074$ \\
${ }^{129} \mathrm{Xe} /{ }^{132} \mathrm{Xe}$ & $2.5^{+2}-1$ & $2.524 \pm 0.002$ \\
\hline
\end{tabular}

Note that in the case of space missions, the He and Ne isotopic ratios could not be measured by any of the probes in the Martian atmosphere. Therefore, there were various attempts to derive Martian atmospheric Ne using Martian meteorites. Such efforts have given a range of ${ }^{20} \mathrm{Ne} /{ }^{22} \mathrm{Ne}$ from 7.0-10.6 [38]. This may indicate the presence of a mixture of several trapped components such as Martian atmosphere and interior for $\mathrm{Ne}$, similar to heavier noble gases [59]. Therefore, the Martian atmospheric Ne composition is not clear. However, precise in situ measurements of Ar and Xe abundances and isotopic ratios were acquired from the SAM instrument onboard the MSL mission. Isotopic ratios of ${ }^{40} \mathrm{Ar} /{ }^{36} \mathrm{Ar},{ }^{38} \mathrm{Ar} /{ }^{36} \mathrm{Ar}$, and ${ }^{129} \mathrm{Xe} /{ }^{132} \mathrm{Xe}$ are in very good agreement with the Martian atmospheric signatures from shock glasses from shergottites, especially EETA 79001 (Figure 2). In the Figure 3, it appears clear that the Ar isotopic signatures in the Martian atmosphere is distinct from SW or terrestrial air composition, and shows low ${ }^{36} \mathrm{Ar} /{ }^{38} \mathrm{Ar} \sim 4$ (compared to a terrestrial ${ }^{36} \mathrm{Ar} /{ }^{38} \mathrm{Ar}=5.32$ and $\left.\mathrm{SW}^{36} \mathrm{Ar} /{ }^{38} \mathrm{Ar}=5.5 \pm 0.2\right)$; therefore, consistent with fractionation loss processes, whereas ${ }^{40} \mathrm{Ar} /{ }^{36} \mathrm{Ar}$ shows the presence of highly radiogenic ${ }^{40} \mathrm{Ar}$ [53]. In addition, the ${ }^{129} \mathrm{Xe} /{ }^{132} \mathrm{Xe}$ ratio for Martian atmosphere is elevated compared to either the solar wind or terrestrial atmosphere. Both Curiosity and Viking measured consistent values for ${ }^{129} \mathrm{Xe} /{ }^{132} \mathrm{Xe}$, which further matches well with the value measured in the meteorite EETA 79001 (Figure 3).

\subsection{Helium}

In Earth's atmosphere, He isotopes (most of ${ }^{3} \mathrm{He}$ and $20-30 \%$ of ${ }^{4} \mathrm{He}$ of the Earth's total inventory) are supplied through continuous degassing at mid-oceanic ridges [66]. In addition, a large fraction of radiogenic ${ }^{4} \mathrm{He}$ is also supplied through degassing of continental crust by magmatic and hydrothermal processes [66]. However, on Mars there are no such continuous degassing sources. The presence of $\mathrm{He}$ on Mars was confirmed with the extreme ultraviolet (EUV) telescope on the satellite EUV Explorer [67]. The lifetime of He in the Martian atmosphere is only $~ 5 \times 10^{4}$ years, compared to 1 Ma on Earth [67], subsequently He constantly escapes from the Martian atmosphere. Thus, the concentration of He is significantly low $(10 \pm 6 \mathrm{ppm})$ [68]. Consequently, incorporation of detectable amounts of Martian atmospheric He in meteorites is not possible through the processes such as adsorption, implantation by shock metamorphism or any other assimilation mechanism as in the case of other noble gases.

\subsection{Neon}

\subsubsection{In Situ Measurements}

Measurement of Ne in the Martian atmosphere was not achieved by Viking due to several instrumental difficulties, mainly due to the doubly ionized species (interferences) for $\mathrm{Ne}$ on Mars, i.e., ${ }^{20} \mathrm{Ne}^{+}$by ${ }^{40} \mathrm{Ar}^{++}$and ${ }^{22} \mathrm{Ne}^{+}$by ${ }^{44} \mathrm{CO}_{2}{ }^{++}$. Even after reducing the ionization energy from $70 \mathrm{eV}$ to $40 \mathrm{eV}$, the interfering species were dominant [18], and Ne was not detected at the limits of the instrument (i.e., $10 \mathrm{ppm}$ ) [20]. Thus, Viking could not make a precise Ne measurement, but the Martian atmospheric ${ }^{20} \mathrm{Ne} /{ }^{22} \mathrm{Ne}$ ratio was assumed to be $10 \pm 3$ [20]. Thereafter, several attempts were made to measure neon trapped in Martian meteorites, which reveals there could be multiple trapped $\mathrm{Ne}$ components, possibly from the atmosphere and interior of Mars. 


\subsubsection{Neon Atmospheric Ratio Revealed by Martian Meteorites}

The noble gases and volatiles (e.g., nitrogen, oxygen, and carbon isotopes) trapped in the vesicles of Martian meteorites such as, e.g., Tissint, serve as proxies to monitor the evolution of the Martian atmospheric volatile and noble gas compositions within the last hundred Ma (e.g., Tissint has an age of $596 \pm 23 \mathrm{Ma}$ ) [69]. In particular, Tissint has proven to be a good candidate in order to have access to the last few hundred Ma of the Martian atmospheric record [46,47], given its short exposure history, with CRE ages ranging from 0.7 to $1.1 \mathrm{Ma}$ [47-71], and therefore a low contribution of cosmogenic isotopes. In addition, Tissint being an observed fall meteorite, it provided minimal contaminated samples. Martian Ne isotopic signatures are rather difficult to characterize since the cosmogenic production usually dominates in the case of Ne isotopes. Therefore, looking for a trapped $\mathrm{Ne}$ component signature is challenging [53]. However, ${ }^{20} \mathrm{Ne} /{ }^{22} \mathrm{Ne}$ ratios have been measured in several Martian meteorites suggesting ${ }^{20} \mathrm{Ne} /{ }^{22} \mathrm{Ne}$ values ranging from 7.0 to 10.6 in the Martian atmosphere. In such studies, a ${ }^{20} \mathrm{Ne} /{ }^{22} \mathrm{Ne}$ ratio of $\sim 10$ has been reported from the analysis of an impact melt in EETA 79001 [35], whereas a ${ }^{20} \mathrm{Ne} /{ }^{22} \mathrm{Ne}$ of $\sim 7$ was measured in of an impact melt extracted from the Yamato (Y) Y-793605 meteorite [61]. Measurements on a pyroxene-rich separate from Dhofar (Dho) 378 gave a ${ }^{20} \mathrm{Ne} /{ }^{22} \mathrm{Ne}=7.3 \pm 0.2$ in agreement with Y-793605 [38]. Park and coworkers explained that such ratio represents the actual value of the Martian atmospheric ${ }^{20} \mathrm{Ne} /{ }^{22} \mathrm{Ne}$ which evolved from an initial ${ }^{20} \mathrm{Ne} /{ }^{22} \mathrm{Ne} \sim 10$, close to $\mathrm{Ne}-\mathrm{Q}$ (Q stands for "quintessence" and represent the main carrier phase of heavy noble gases- $\mathrm{Ar}, \mathrm{Kr}$, and $\mathrm{Xe}$ - in chondrites [72]), and which therefore explains all previous measurements of ${ }^{20} \mathrm{Ne} /{ }^{22} \mathrm{Ne} \sim 10$ [38]. Figure 4 shows the Ne-three isotope plot $\left({ }^{20} \mathrm{Ne} /{ }^{22} \mathrm{Ne}\right.$ vs. $\left.{ }^{21} \mathrm{Ne} /{ }^{22} \mathrm{Ne}\right)$ based on the compilation of Ne measurements on Martian meteorites from the literature [73]. We plotted, in addition, the Ne data measured on 18 Martian meteorites (mostly shergottites, including Tissint) and one nakhlite [47], on the Ksar Ghilane 002 (KG 002) shergottite [74], on the Yamato Y-000593 nakhlite [75,76], on the Yamato shergottites Y-000027 and Y-000097 [76], as well as the recent data obtained on and NWA 7034 [77]. The samples measured by Wieler and co-workers were degassed at $1700{ }^{\circ} \mathrm{C}$ in a single step [47]. The KG 002 was heated in steps of 600,1000 , and $1800{ }^{\circ} \mathrm{C}$ [74], and the Yamato Y-000593, Y-000027 and Y-000097 samples were heated in steps of 500, 1000,1400 , and $1800{ }^{\circ} \mathrm{C}[75,76]$. Two samples of Y-000593 have been vacuum-crushed [75]. The NWA 7034 samples were heated in steps of 600,1000 , and $1800{ }^{\circ} \mathrm{C}$ [77]. The data tend to indicate a mixture between a cosmogenic endmember and a trapped endmember, probably Earth atmosphere through contamination or Martian atmosphere. Most of the data plot close to the cosmogenic endmember, therefore indicating contributions from GCRs, and possibly minor contributions from SCRs. The most significant shift towards a trapped component is observed on one of the crushed Y-000593 samples [75]. Assuming Martian atmosphere as a trapped endmember, the majority of the data would suggest a ${ }^{20} \mathrm{Ne} /{ }^{22} \mathrm{Ne}$ ratio of $\sim 10$, as reported, e.g., in [35]. However, the data on the Martian shergottite KG 002 $\left(600{ }^{\circ} \mathrm{C}\right.$ heating step) (Figure 4) tend to confirm the possible ${ }^{20} \mathrm{Ne} /{ }^{22} \mathrm{Ne}=7.3$ as representative of the Martian atmosphere and is consistent with previous studies on, e.g., the regolith breccia NWA 7034 [38]. Nevertheless, the Martian atmospheric ${ }^{20} \mathrm{Ne} /{ }^{22} \mathrm{Ne}$ ratio remains not properly constrained. As shown recently, the trapping mechanisms of Ne in Martian meteorites appears to work in a similar way to the entrapment of noble gases in tektites [38]. Elemental abundances of noble gases in previously measured tektites indicate anomalous $\mathrm{Ne}$ enrichments relative to air. In addition, this suggests that $\mathrm{Ne}$ diffused in the tektites from the atmosphere [78]. Such mechanisms need to be clearly understood in order to better derive the Martian atmospheric ${ }^{20} \mathrm{Ne} /{ }^{22} \mathrm{Ne}$ ratio and investigate the implications for Mars atmosphere evolution. More Martian meteorites (shergottites) with low CRE ages, such as Tissint, need to be analyzed in this context: we can evoke, among others, NWA 4925, NWA 1195, NWA 2046, NWA 2626, NWA 5789, DaG 476, SaU 005, or Y-980459. All of those samples are shergottites and have ejection ages (the sum of their CRE ages and terrestrial ages) around $\sim 1 \mathrm{Ma}$ [70]. As different noble gas components can be retained in different sites within the meteorites, a combination of both vacuum crushing and stepwise heating are crucial to unravel the trapping mechanisms of noble gases [38]. 


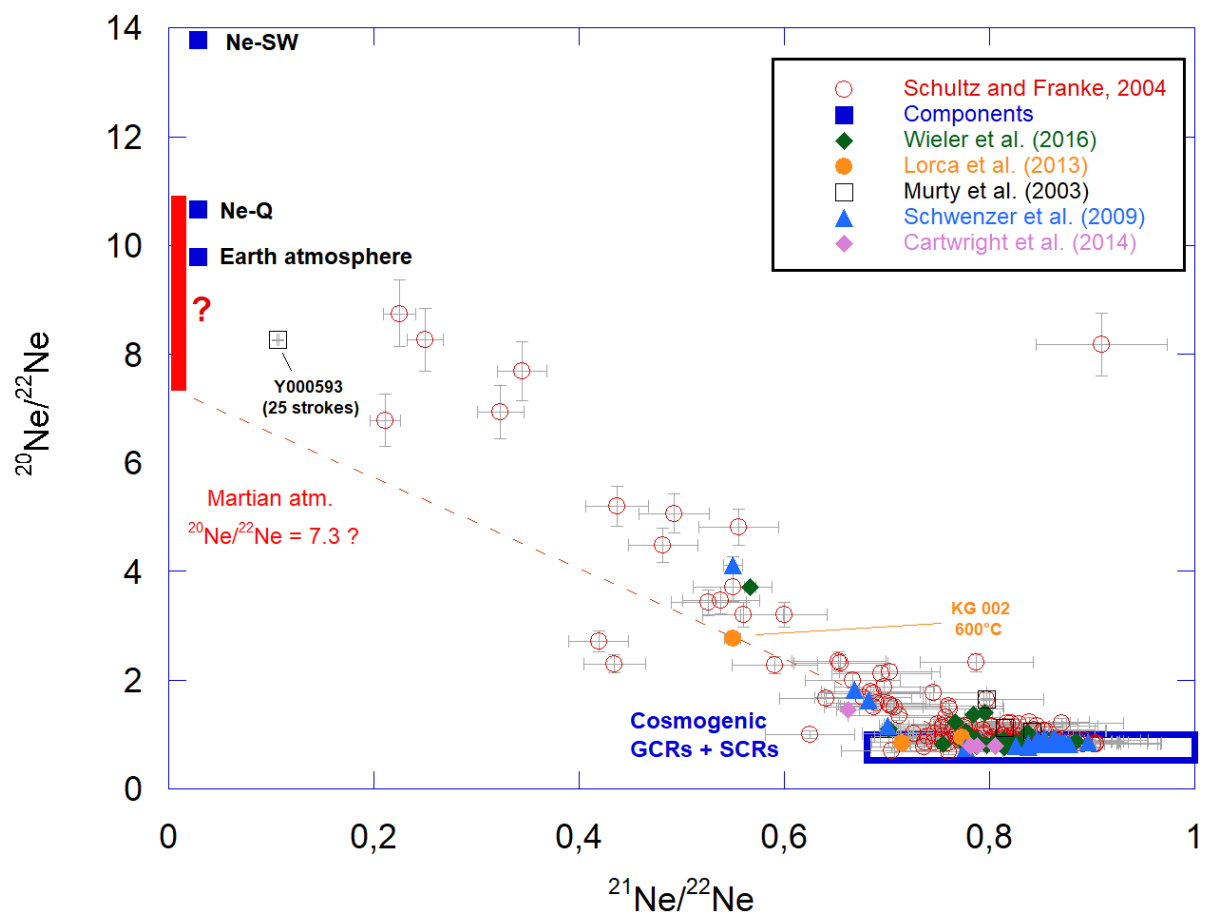

Figure 4. Neon-three isotope plot for measured Martian meteorites [47-73], Y000593, Y000027, Y000097 [75,76], and NWA 7034 [77]. The terrestrial atmosphere, Ne-Q, and Ne-SW components are also reported. Error bars are reported in light gray. The thick red line represents the range of $\mathrm{Ne}$ isotopic ratios for the Martian atmosphere, as reported in [35-61]. Adapted and modified after the works in [36-61].

\subsection{Argon}

\subsubsection{MOM\&MAVEN: Measurements in the Well-Mixed Atmosphere}

Both MAVEN and MOM missions acquired, among others, the concentration of the Martian exospheric Ar; the MENCA instrument has measured the Ar number density during four orbits when MOM was the closest to Mars (i.e., $265 \mathrm{~km}$ ). During these phases, the concentrations, and variations in major species such as $\mathrm{O}, \mathrm{N}_{2}$, and $\mathrm{CO}$ or $\mathrm{CO}_{2}$ were as well monitored.

At the given exospheric temperatures, Ar is not condensable, thus one does not expect any drastic variation due to temperature changes within this interval. However, both NGIMS onboard MAVEN and MENCA onboard MOM have noticed daily variations and changes in the slope of Ar profiles in the exospheric altitudes ranging from $\sim 210 \mathrm{~km}$ to $\sim 260 \mathrm{~km}$.

The observed increase in scale height has therefore been explained by the presence of a suprathermal component in this region (i.e., the upper exospheric region); these particles might be generated by collisional sputtering. For example, solar wind-induced sputtering is responsible for the loss of atmospheric species such as noble gases [34-79]. This phenomenon occurs when hot oxygen ions in the Martian corona are picked up, thus initiating escape to space of the exospheric neutrals. Thus, it has been inferred that $66 \%$ of atmospheric argon has been lost to space [79].

\subsubsection{Loss of Atmospheric Argon to Space Confirmed by Martian Meteorite and Mission Data}

\section{Elemental Abundances}

The SAM suite onboard Curiosity measured the abundance and isotopic composition of Ar in the Martian atmosphere. In addition to the main atmospheric constituents (about $95 \% \mathrm{CO}_{2}$ and variable amounts of $\mathrm{H}_{2} \mathrm{O}$, Table 2), the Martian atmosphere contains $2.7 \%$ of $\mathrm{N}_{2}$ and $1.6 \%$ of Ar. Interestingly, the relative abundances of the noble gases $\mathrm{Ne}, \mathrm{Ar}, \mathrm{Kr}$, and $\mathrm{Xe}$ are similar to the ones in 
the Earth's atmosphere, although the atmospheric pressure on Mars only represents $\sim 1 \%$ of the one on Earth.

The $\mathrm{Ar} / \mathrm{N}_{2}$ ratio, previously found to be $\sim 0.35 \pm 0.08$ by Viking [20], is close to unity $\left(\mathrm{Ar} / \mathrm{N}_{2} \sim 1.2\right)$ [40]. Such differences can be explained by invoking different instrumental characteristics, i.e., in the case of SAM, the use of turbomolecular pumps to evacuate the instrument thought to produce more accurate results than the only small ion pumps onboard Viking [4]. The new value of the ${ }^{40} \mathrm{Ar} / \mathrm{N}_{2}$ ratio of 1.2, suggests a more vigorous outgassing of ${ }^{40} \mathrm{Ar}$ from the interior of Mars than previously recognized [40]. Moreover, the ${ }^{40} \mathrm{Ar} /{ }^{14} \mathrm{~N}$ ratio is frequently used to assess the degree of mixing between the atmospheric and mantle gas components in shocked glasses of Martian meteorites.

\section{Isotopic Ratios}

As shown in Figure 3, SAM measured a ${ }^{40} \mathrm{Ar} /{ }^{36} \mathrm{Ar}$ value of $1900 \pm 300$ [40]; it is in rather good agreement with the ratios measured in Martian meteorites such as EETA $79001\left({ }^{40} \mathrm{Ar} /{ }^{36} \mathrm{Ar} \sim 2050 \pm 70\right)$ [63], but not consistent with the previous measurements by Viking (i.e., ${ }^{40} \mathrm{Ar} /{ }^{36} \mathrm{Ar} \sim 3000 \pm 500$ ) [20]. In addition, a recent combined noble gases-nitrogen study of the Tissint meteorite has dedicated one set of samples (two "Aggregates" and one "Glass") for combined Ar-N measurements [31-46]. A ${ }^{40} \mathrm{Ar} /{ }^{\beta 6} \mathrm{Ar}$ ratio of about $1714 \pm 170$ has been measured in these Tissint samples and is therefore in good agreement with the in situ measurement on mars by Curiosity mission [46]. Therefore, the value obtained by the Viking mission was probably overestimated. The present-day Martian atmospheric ${ }^{40} \mathrm{Ar} /{ }^{\beta 6} \mathrm{Ar}$ ratio, estimated to be of $\sim 1800 \pm 100$, is therefore high relative to the Martian interior isotopic ratio of ${ }^{40} \mathrm{Ar} /{ }^{36} \mathrm{Ar} \leq 212$ [63].

The SAM ${ }^{40} \mathrm{Ar} /{ }^{36} \mathrm{Ar}$ ratio, therefore, highlights the enrichment of Martian atmosphere in radiogenic ${ }^{40} \mathrm{Ar}_{\text {rad }}$ compared to ${ }^{36} \mathrm{Ar}$, which is interpreted as an evidence of a significant loss to space of the primordial Martian atmosphere, with subsequent partial degassing of Ar [40]. Loss of primary atmosphere indeed favors enrichments in ${ }^{40} \mathrm{Ar}$ over ${ }^{36} \mathrm{Ar}$, associated with the measured fractionated ${ }^{36} \mathrm{Ar} /{ }^{38} \mathrm{Ar}$ ratio of $4.2 \pm 0.1$ (Figure 3), much lower than the Earth, chondritic, or even Jovian values ranging from 5.3 to 5.6 [80-82]. This ${ }^{36} \mathrm{Ar} /{ }^{38} \mathrm{Ar}$ ratio is the lowest measured on any planetary material in the solar system, except in some Martian meteorites; indeed, it is matching exactly with the value measured from Martian meteorites, for example, ${ }^{36} \mathrm{Ar} /{ }^{38} \mathrm{Ar}=4.1 \pm 0.2$, from EETA 79001 [39]. Thus, the new data from Curiosity further confirms that the trapped gases in meteorites from Mars represent the current Martian atmosphere. This new value slightly differs from the previous ${ }^{36} \mathrm{Ar} /{ }^{38} \mathrm{Ar}$ ratio estimation by Viking of $5.5 \pm 1.5$ [20]. Similar trends have been observed for the $\mathrm{D} / \mathrm{H},{ }^{14} \mathrm{~N} /{ }^{15} \mathrm{~N}$, ${ }^{12} \mathrm{C} /{ }^{13} \mathrm{C}$, or ${ }^{16} \mathrm{O} /{ }^{18} \mathrm{O}$ ratios, which show a preferential loss of the lighter isotopes, and an enrichment in the heavier [40]. Such low value of the ${ }^{36} \mathrm{Ar} /{ }^{38} \mathrm{Ar}$ ratio has probably been acquired by a balance between the Martian atmospheric loss through the solar wind erosion, and the outgassing of a solar-derived mantle Ar isotopic signature (i.e., ${ }^{36} \mathrm{Ar} /{ }^{38} \mathrm{Ar}=5.5$ ) [44]. Therefore, this measurement provides a strong constraint on Martian atmosphere loss to space in the last 4 Ga [44]. To account for the present-day measured ${ }^{36} \mathrm{Ar} /{ }^{38} \mathrm{Ar}$ ratio, a significant fraction of the original Martian atmospheric argon is required [44]. Argon-36 is the major (98\%) decay product of ${ }^{36} \mathrm{Cl}\left(T_{1 / 2}=3 \times 10^{5}\right.$ years), whereas ${ }^{38} \mathrm{Ar}$ in meteorites and Martian soil is produced (not only) by spallogenic reaction on chlorine in surface rocks, following the reaction ${ }^{37} \mathrm{Cl}(\mathrm{n}, \gamma)^{38} \mathrm{Ar}$ [83]. A low ${ }^{36} \mathrm{Ar} /{ }^{38} \mathrm{Ar}$ ratio would therefore imply low chlorine concentrations $(<0.1 \mathrm{wt} \%)$ [32]. However, the chlorine concentrations in the surface rocks of Mars could not explain this low ${ }^{36} \mathrm{Ar} /{ }^{38} \mathrm{Ar}$ ratio; based on the average (large) $\mathrm{Cl}$ concentrations, the Martian ${ }^{36} \mathrm{Ar} /{ }^{38} \mathrm{Ar}$ should be higher than the measured value by SAM, which would, therefore, imply a greater atmospheric loss [32]. The SAM-QMS measured the ${ }^{14} \mathrm{~N} /{ }^{15} \mathrm{~N}$ separately using an enrichment technique [84]. Nitrogen isotopes also support the atmospheric loss process but might suffer from effects of reservoirs of nitrogen compounds in the crust [84]. In addition, signatures of an ancient Martian atmosphere were identified through a combined noble gases-nitrogen study in ALH 84001 [85]. Trapped Mars atmospheric gas in ALH84001 shows signatures of elemental and isotopic compositions significantly different to the composition found in the 180 Ma year old EETA 79001 [85]. Based on this, the authors conclude that a thicker Martian atmosphere must have existed at 
the beginning, which may have subsequently escaped to space. However, a modeling study based on surface meteorite mineralogy, coupled with trapped Ar measured in ALH 84001, concluded that Mars did not have a thick ancient atmosphere. This also implied that the Noachian ( $>3.7 \mathrm{Ga}$ ) period on Mars was cool and dry with only intermittent warm and wet conditions [86].

\subsection{Krypton and Xenon}

\subsubsection{Elemental and Isotopic Abundance Patterns}

Krypton and xenon have been first detected in the Martian atmosphere by the Viking landers. Although it was challenging to give the precise abundances and isotopic ratios of $\mathrm{Kr}$ and $\mathrm{Xe}$ in the Martian atmosphere, there are no doubts about the fact that elemental $\mathrm{Kr}$ is more abundant than elemental $\mathrm{Xe}$, which is the reverse as what is commonly observed in the primordial gas component of ordinary or carbonaceous chondrites, see, e.g., in [19-72] (Figure 5). The Martian lower atmosphere has been found to contain $0.3 \mathrm{ppm}$ of $\mathrm{Kr}$ and $0.08 \mathrm{ppm}$ of Xe (Table 2) [18].

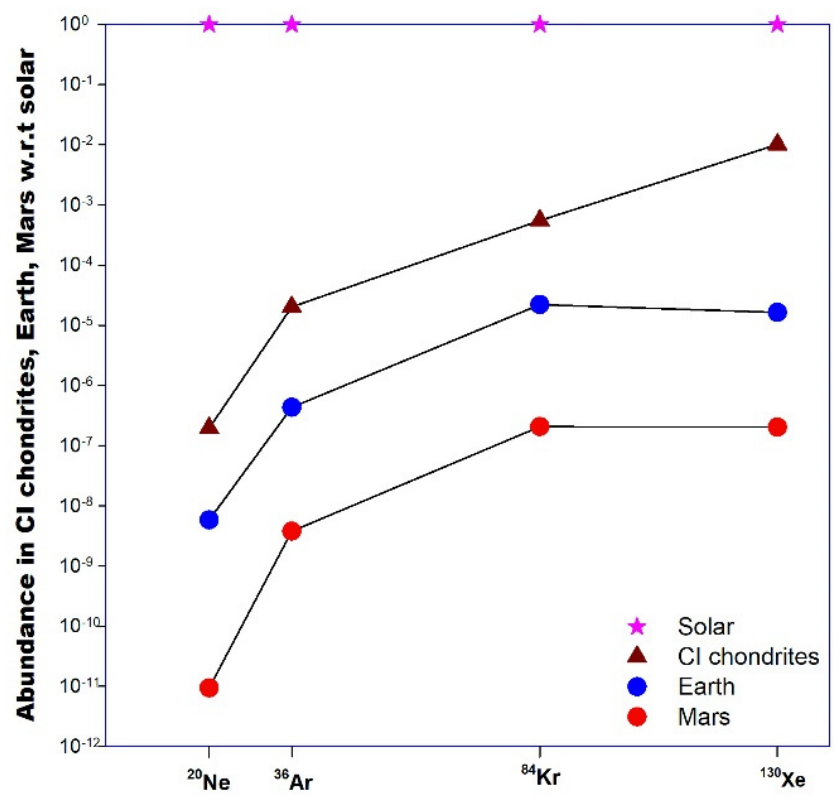

Figure 5. Elemental noble gas abundance patterns of the Earth, Mars, CI meteorites, normalized to solar values. The atmospheres of Earth and Mars are depleted in Xe compared to chondrites.

\section{Krypton}

In the mass spectra obtained from the Viking mission, the presence of a broad peak at mass $m / e=80$ could be interpreted as an artefact being due to a high concentration of ${ }^{40} \mathrm{Ar}$ in the instrument [65]. Krypton-80 excesses detected by SAM onboard Curiosity are, however, inconsistent with any artifact issue given that the SAM instrument appears to be free of possible interfering species [41]. The observed ${ }^{80} \mathrm{Kr}$ excesses can be due to neutron capture on ${ }^{79} \mathrm{Br}$ induced by GCRs, as previously identified in EETA 79001 [87] (Table 1); in addition, such ${ }^{80} \mathrm{Kr}$ excesses can be explained by a $43 \%$ degassing of the regolith produced over 3.7 Ga by the interaction with GCRs [41]. The recent research by Cartwright et al., 2014 reported an excess in ${ }^{80} \mathrm{Kr}$ and ${ }^{82} \mathrm{Kr}$ in the Martian meteorite NWA 7034, indicating neutron capture on $\mathrm{Br}$, which corroborates the observations made by Curiosity [77]. Interestingly, these authors found a modern Martian atmosphere signature rather than the ancient Martian atmospheric component reported earlier [64]. In a recent work, the study of the Tissint Martian meteorite revealed excesses in the lighter isotopes of $\mathrm{Kr}$ but to some extent lower than what has been observed earlier by Curiosity [46]. 
Xenon

The xenon spectra from the Viking mission shows a clear enrichment in ${ }^{129} \mathrm{Xe}$ compared to the other isotopes ${ }^{131,132} \mathrm{Xe}$ (e.g., ${ }^{129} \mathrm{Xe} /{ }^{132} \mathrm{Xe} \sim 2.5^{+2}{ }_{1}$, Figure 3), whereas those three isotopes are equally as abundant in the Earth atmosphere (e.g., $\left.{ }^{129} \mathrm{Xe} /{ }^{132} \mathrm{Xe} \sim 0.98\right)$. The ${ }^{129} \mathrm{Xe} /{ }^{132} \mathrm{Xe}$ ratio measured by Curiosity $\left({ }^{129} \mathrm{Xe} /{ }^{132} \mathrm{Xe} \sim 2.52\right)$ [41] agrees very well with the previous data obtained from the Viking mission $[19,20]$. In both cases, the measured ratios at Mars are consistent with the range of values measured in Martian meteorites (cf. Figure 3). To explain such enrichments in ${ }^{129} \mathrm{Xe}$, Owen et al., 1976 [19] evoked, among other hypotheses, (i) the result from the production of ${ }^{129}$ Xe by decay of ${ }^{129} \mathrm{I}$; (ii) the possible origin of the Martian atmosphere from a partially degassed C-1-type meteorite: the reported ${ }^{129} \mathrm{Xe} /{ }^{132} \mathrm{Xe}$ ratios in carbonaceous and in ordinary chondrites range from 4.5-9.6 (see in [19] and references therein). Meteorites of types C-3 to C-4 generally retain more noble gases, and ${ }^{129} \mathrm{Xe}$ in particular, than chondrite types C-1 or C-2 [88]; (iii) possible massive losses of the Martian atmosphere after planet formation [19]. In addition, the xenon isotopic abundances measured by the SAM suite of instruments onboard the Curiosity mission led to the following conclusions. (i) Excesses in ${ }^{124,126} \mathrm{Xe}$ have been detected by SAM, such enhancement being the result of spallation processes (spallation and neutron capture products, outgassed from the Martian regolith) produced by GCRs on Ba and some other Rare Earth Elements (REEs) [41]; (ii) similarly to Viking three decades ago, notable excesses in ${ }^{129}$ Xe have been detected by SAM [41]; such enrichments could be explained by an outgassing of radiogenic ${ }^{129} \mathrm{Xe}_{\text {rad }}$. Besides, none of the heavy Xe isotopes measured by the SAM showed expected enrichments when considering a ${ }^{244} \mathrm{Pu}$ fission [41]. However, clear fission contributions from both ${ }^{238} \mathrm{U}$ and ${ }^{244} \mathrm{Pu}$ in the Xe data of, e.g., NWA 7034 were identified, causing an excess in ${ }^{136} \mathrm{Xe}$ [77].

\subsubsection{Isotopic Ratios}

\section{Krypton}

Martian $\mathrm{Kr}$ isotopic measurements in Martian meteorites show either indistinguishable composition as those in solar wind (SW) or are isotopically fractionated reverse from terrestrial atmospheric $\mathrm{Kr}$ [9]. In Figure 6, we report the $\mathrm{Kr}$ isotopic composition based on several Martian meteorite measurements, normalized to SW-Kr. The enrichments observed in ${ }^{80} \mathrm{Kr}$ and ${ }^{82} \mathrm{Kr}$ are attributed to neutron capture production on ${ }^{79} \mathrm{Br}$ and ${ }^{81} \mathrm{Br}$, respectively [9-41].

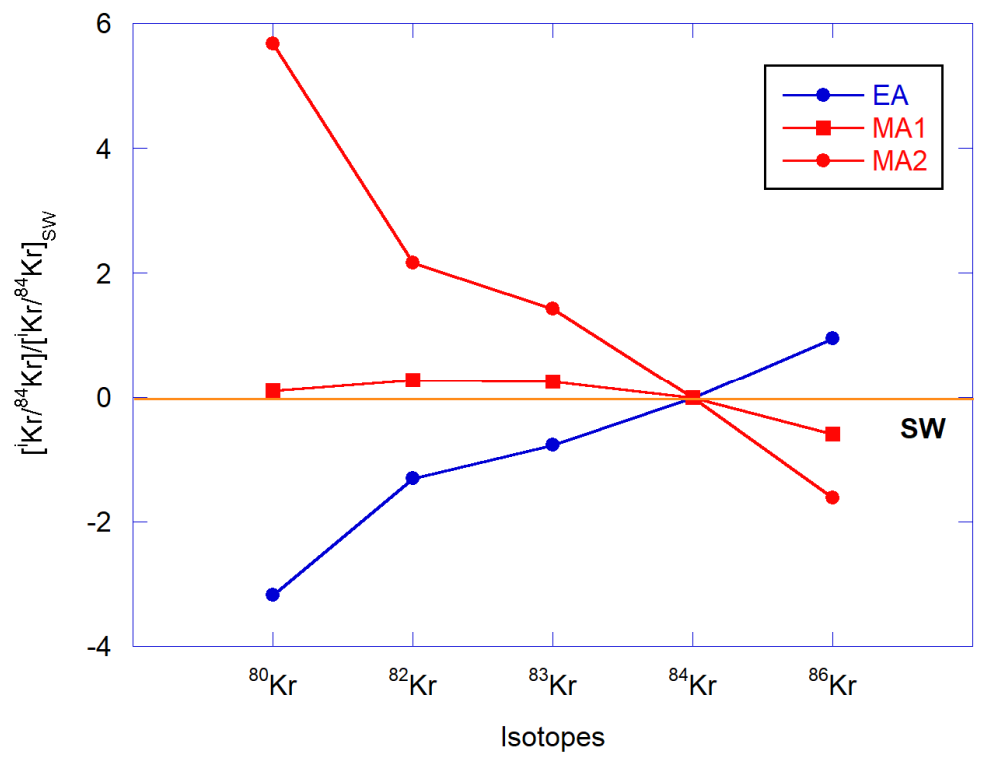

Figure 6. Kr isotopic composition in Earth and Mars atmospheres (EA and MA, respectively) measured in a glass of EETA 79001 [36-61]. All data are normalized to ${ }^{84} \mathrm{Kr}$ and to solar wind krypton (SW-Kr, orange line). Adapted and modified from the work in [9]. 
As mentioned earlier in this review, vacuum crushing of Martian meteorites was undertaken aimed at identifying the Martian atmospheric noble gas signatures which have been trapped in the glass bubbles. However, a previous study reported that the heavy noble gas isotopic signatures on the meteorite EETA 79001 might be indistinguishable from the terrestrial atmosphere, see, e.g., in [51-53]. It, therefore, defines a "crush component", indigenous, so-called EETV [51]. This EETV component can be considered as a third component in shergottites, together with Martian atmosphere and Martian interior [53]. It appears to be sited in the 10-100 $\mu \mathrm{m}$ diameter vesicles [51]. Its composition might be responsible for the observed shift of some shergottite noble gas data points along the Chassigny-Martian atmosphere mixing line [53]. The EETV component has a $\mathrm{Kr}$ isotopic composition similar to the terrestrial $\mathrm{Kr}$, no enrichments in ${ }^{80} \mathrm{Kr}$ due to neutron capture on $\mathrm{Br}$ are noticed (Figure 7), whereas its $\mathrm{Xe}$ isotopic composition in indistinguishable from either terrestrial or Martian atmospheres [53]. The EETV component could represent a second "interior" component within the cracks of the samples; during the shock producing the impact glass, a mixture between molten material and Martian atmospheric gas could occur, resulting in the EETV component isotopic signature [51]. However, up to date, little is known about the EETV component, which therefore calls for further investigations of (heavy) noble gases isotopic signatures released by crushing experiments.

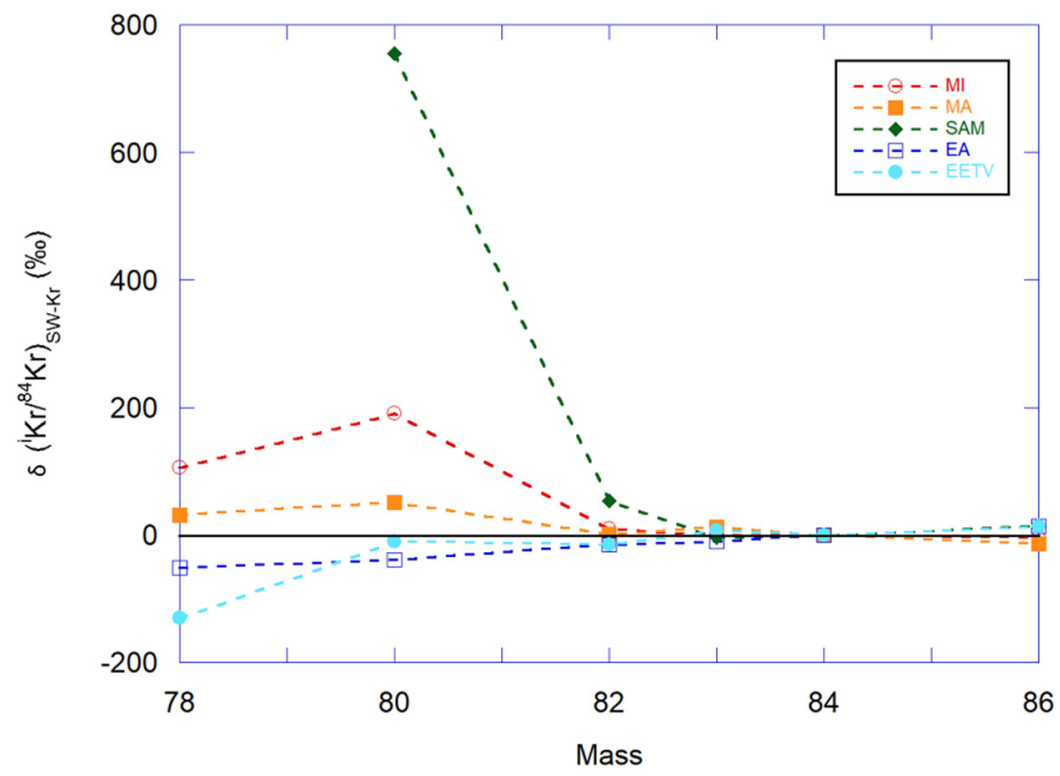

Figure 7. $\mathrm{Kr}$ isotopic composition in Earth and Mars atmospheres (EA and MA, respectively), Mars Interior (MI) and Curiosity (SAM) data ([53], and references therein). Isotopic compositions are given using the delta notation, normalized to ${ }^{84} \mathrm{Kr}$ and to solar wind krypton (SW-Kr, black line), following the formula: $\delta^{i} \mathrm{Kr}_{\mathrm{SW}-\mathrm{Kr}}=1000 \times\left(\frac{\left(\frac{\mathrm{i}_{\mathrm{Kr}}}{84 \mathrm{Kr}}\right)_{\text {component }}}{\left(\frac{\mathrm{i}_{\mathrm{Kr}}}{84 \mathrm{Kr}}\right)_{\mathrm{SW}-\mathrm{Kr}}}-1\right)$. Error bars are omitted for the clarity of the data. Adapted and modified from the work in [53].

Xenon

The Xenon isotopic signatures on Mars: Figure 8 shows a Xe three-isotope plot $\left({ }^{136} \mathrm{Xe} /{ }^{132} \mathrm{Xe}\right.$ vs. ${ }^{129} \mathrm{Xe} /{ }^{132} \mathrm{Xe}$ ), based on Martian meteorite measurements, in situ measurements, as well as terrestrial and solar isotopic compositions [89]. It defines different trapped Xe "components" associated with distinct Xe isotopic signatures, spallation and fission reactions, as well as ${ }^{129} \mathrm{I}$ decay are responsible for these different isotopic signatures. Based on this figure, there is a clear distinction between Xe isotopic composition in Mars atmosphere (MA) and Earth atmosphere (EA). In addition, the Xe isotopic composition in the Mars interior (MI) plots close to SW isotopic signature. Based on these isotopic signatures, three components are clearly identified: Martian atmosphere [90], Martian interior [27] and radiogenic/fissiogenic products (due to fission reactions of ${ }^{244} \mathrm{Pu}$ and ${ }^{238} \mathrm{U}$ ). The component 
"Chass S" represents a solar-like Xe component and "Chass E" represents a more evolved component with ${ }^{244} \mathrm{Pu}$-derived fission Xe in Chassigny [64]. In addition, Xe isotopic signatures of ALH 84001 indicate the presence of ${ }^{244} \mathrm{Pu}$-derived fission Xe on Mars [64]. The elevated ${ }^{129} \mathrm{Xe} /{ }^{132} \mathrm{Xe}$ value for Martian atmosphere is due to the degassing of mantle with high I/Xe before ${ }^{129} \mathrm{I}$ became extinct [89]. Thus, more ${ }^{129} \mathrm{Xe}$ is produced compared to other Xe isotopes due to the combined effects of ${ }^{129} \mathrm{I}$ decay from surface rocks and early atmosphere loss due to solar wind sputtering [89].

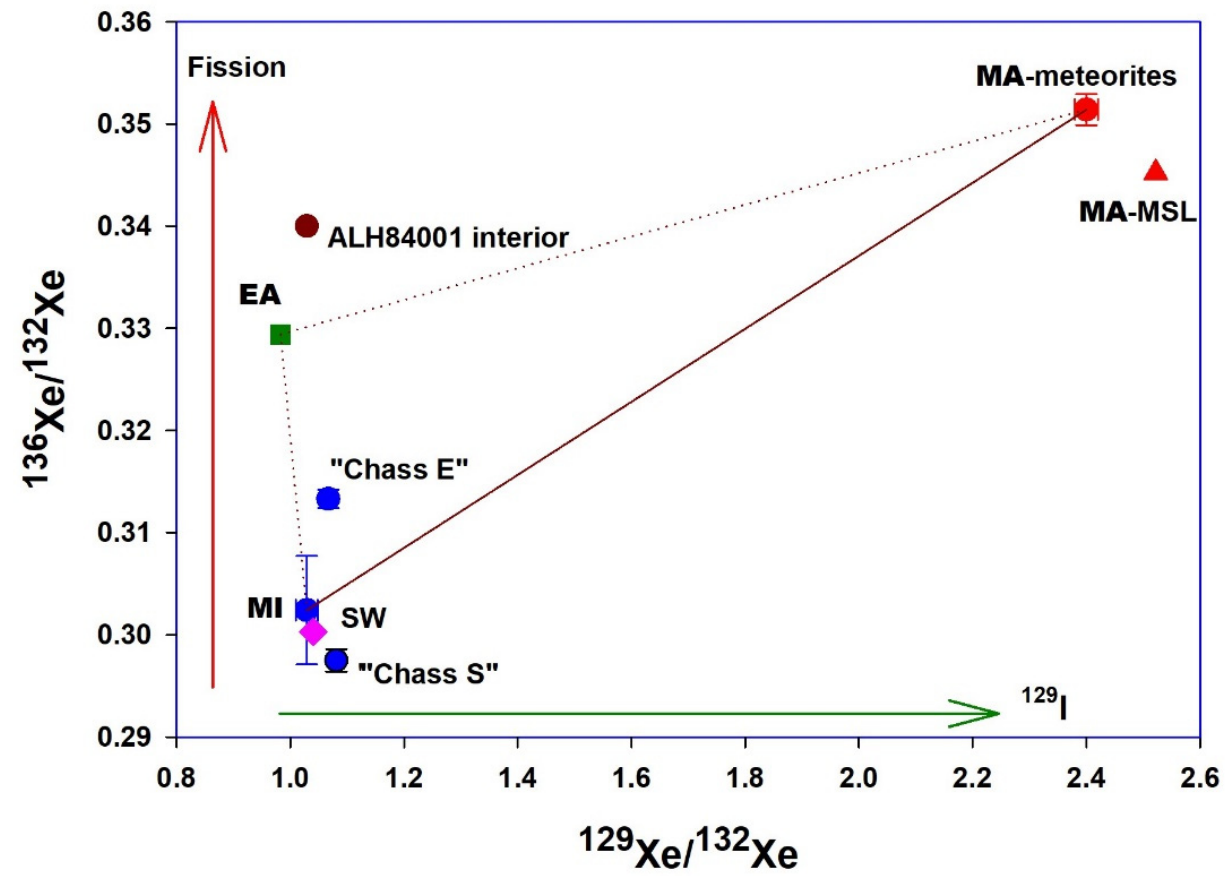

Figure 8. Xenon three-isotope plot of ${ }^{136} \mathrm{Xe} /{ }^{132} \mathrm{Xe}$ vs. ${ }^{129} \mathrm{Xe} /{ }^{132} \mathrm{Xe}$ showing different Martian Xe components. The solid line represents the mixing line between Mars atmosphere and interior, while the dotted line represents terrestrial contamination of Mars atmosphere and interior components. The effects of fission and ${ }^{129}$ I decay are also shown. Martian atmosphere and interior components based on meteorite data are from [27-90]. In situ Martian atmosphere is from the work in [41]. In the figure EA: Earth atmosphere, MA: Mars Atmosphere, MI: Mars interior, SW: solar wind, MSL: Mars Science Laboratory. Adapted and modified from [89].

Loss of primary atmosphere based on Xe isotopic measurements: The abundance of Xe in the atmosphere of Mars (and by extension in the Earth's atmosphere) is lower than what is predicted by assuming that noble gas abundances follow the same pattern as in chondrites [91]. This elemental depletion is coupled with observed enrichments in the heavy Xe isotopes compared to the light ones, normalized to the Xe abundances in e.g., chondrites, or solar wind (SW), as shown in Figure 9. Mars and the Earth are enriched in heavy Xe isotopes compared to the abundances in the so-called Xe-Q, found in the phase- $Q$ of chondrites ( $Q$ represents the main carrier phase of noble gases in chondrites) [91]. This phenomenon is known as the "xenon paradox" [1].

Both Earth and Mars display similar features in their Xe isotopic composition, which is still not properly understood, given their evolutionary differences. Delivery of an extra solar-like $\mathrm{Kr}$ might explain, e.g., the similar ${ }^{84} \mathrm{Kr} /{ }^{132} \mathrm{Xe}$ in the atmospheres of the Earth and Mars [92]. The Earth is considered to have lost its primary atmosphere by escape caused by asteroid impacts [35]; volatiles were later supplied to the Earth by asteroids or comets [17]. The noble gas inventories of the Earth's mantle showed two sources as contributors: a solar component, identified in Ne isotopes [93], and a chondritic component, identified in $\mathrm{Kr}$ and Xe isotopic compositions [94,95]. After correction for a mass-dependent fractionation, the Earth's atmosphere is depleted in heavy Xe isotopes $\left({ }^{134,136} \mathrm{Xe}\right)$ relative to solar or chondritic signatures [35]. The "U-Xe" is therefore defined as the Xe modern terrestrial atmospheric 
precursor and characterized by a solar composition in light Xe isotopes $\left({ }^{124-130} \mathrm{Xe}\right)$ and a depleted composition in heavy isotopes [35]. The U-Xe was first theoretically defined by using meteorite data to obtain a best fit to the atmospheric Xe [96]. Later, the U-Xe was suggested to be a mixture of both cometary and chondritic Xe [17]. Unlike the Earth, Mars atmospheric Xe precursor does not appear to be U-Xe, but SW-Xe, as shown by the Xe isotopic data of the Chassigny meteorite [27]. Being the heaviest noble gas, $\mathrm{Xe}$ is less likely to be removed from the atmospheres by any mass-dependent thermal processes [91]. In particular, the significant enrichments in heavy Xe isotopes observed in the Martian atmosphere could be explained by a preferential loss of light Xe isotopes to space by hydrodynamic escape [33-35]. Such hydrodynamic escape is caused by the extreme ultraviolet conditions in the early Martian history caused by the young evolving fast rotating Sun, and responsible for the dissipation of primary planetary atmospheres on low-gravity planetary bodies [30-35]. Xenon is indeed thought to be too heavy to be affected and fractionated by other mass-dependent thermal processes [33]. The timing of the Martian atmospheric loss was first inferred from the study of the Xe isotopic composition of the Allan Hills ALH 84001 Martian meteorite [96]. The trapped Xe isotopic composition of ALH 84001 revealed a lower ${ }^{129} \mathrm{Xe} /{ }^{132} \mathrm{Xe}$ ratio $(1.95 \pm 0.2)$ than the present-day atmospheric Martian Xe [97]. This fact coupled with lower excess ${ }^{136} \mathrm{Xe} /{ }^{129} \mathrm{Xe}$ ratios excluded a possible gas mixture [90]. However, Cassata, 2017 showed that the composition of atmospheric Xe in ALH 84001 is indistinguishable from modern Martian atmospheric composition [33]. With an age of $\sim 4.2 \mathrm{Ga}$, the Xe isotopic composition of ALH 84001 therefore indicated that atmospheric escape might have occurred in the really early planet's history and stopped at $\sim 4.4-4.0$ Ga [33-91]. Magmatism is a potential explanation for the increase of the ${ }^{129} \mathrm{Xe} /{ }^{132} \mathrm{Xe}$ ratio to the modern value around 4.2-4.3 Ga [33].

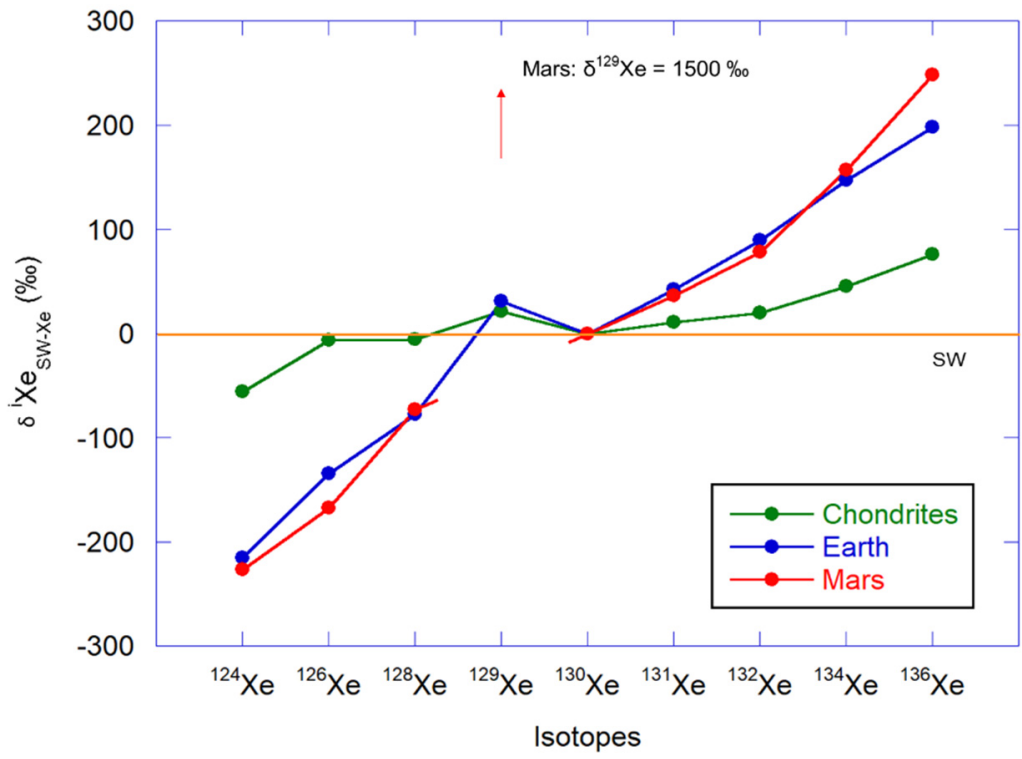

Figure 9. Xe isotopic composition in Earth and Mars atmospheres [resp. ([1-80]), compared to chondritic Xe isotopic compositions [72]. Isotopic compositions are given using the delta notation, normalized to ${ }^{130} \mathrm{Xe}$ and to solar wind xenon (SW-Xe, orange line), following the formula: $\delta^{\mathrm{i}} \mathrm{Xe}_{\mathrm{SW}-\mathrm{Xe}}=$ $1000 \times\left(\frac{\left(\frac{\mathrm{i} X_{e}}{130 X_{e}}\right)_{\text {component }}}{\left(\frac{\mathrm{i} X_{e}}{130 \mathrm{Xe}_{\mathrm{e}}}\right)_{S W-\mathrm{Xe}_{e}}}-1\right)$. Adapted and modified from Avice and Marty (2020) [91].

\subsection{Elemental and Isotopic Heavy Noble Gas Ratios}

Krypton and xenon, with, respectively, six and nine isotopes, are particularly useful to decipher the early evolutionary processes as well as the isotopic fractionation processes in the Solar System [1]. Figures 10 and 11 hereafter represent the plots of ${ }^{129} \mathrm{Xe} /{ }^{132} \mathrm{Xe}$ vs. ${ }^{36} \mathrm{Ar} /{ }^{132} \mathrm{Xe}$ and ${ }^{129} \mathrm{Xe} /{ }^{132} \mathrm{Xe}$ vs. ${ }^{84} \mathrm{Kr} /{ }^{132} \mathrm{Xe}$ in Martian meteorites, respectively. Such diagrams are commonly used to demonstrate the mixing patterns of $\mathrm{Ar}, \mathrm{Kr}$ and Xe between different reservoirs [53]. In Figure 10, we plotted the 
${ }^{129} \mathrm{Xe} /{ }^{132} \mathrm{Xe}$ ratio versus the trapped ${ }^{36} \mathrm{Ar} /{ }^{132} \mathrm{Xe}$ ratio based on the literature data for Martian meteorites (EETA 79001, Shergotty, Nakhla, ALH 84001, etc.) compiled by Bogard and Garrison, 1998 [98]. The isotopic compositions of the Earth's atmosphere, as well as measurements from Viking [20] and on Martian meteorites (both from shergottites and nakhlites) are plotted. The data show a clear mixing between Mars interior (Chassigny is thought to represent Martian interior component) [9-53], and another component, with an isotopic signature close to some of the EETA 79001 and Shergotty data. Thus, the measurements on glass data by Bogard and Garrison, 1998 [98] suggest Martian atmospheric ratios of ${ }^{36} \mathrm{Ar} /{ }^{132} \mathrm{Xe} \sim 900 \pm 100$ and ${ }^{129} \mathrm{Xe} /{ }^{132} \mathrm{Xe} \sim 2.60 \pm 0.05$, as shown in Figure 10. In the case of some meteorite data (e.g., Zagami or one EETA 79001 sample in the Figure 10), a shift towards the terrestrial atmosphere component is visible; the reason invoked for such a shift might be due to contamination by terrestrial air [53-98].

The plot in Figure 11 represents the Xe three isotope diagram $\left({ }^{129} \mathrm{Xe} /{ }^{132} \mathrm{Xe}\right.$ vs. $\left.{ }^{84} \mathrm{Kr} /{ }^{132} \mathrm{Xe}\right)$ of the same literature data for Martian meteorites as for Figure 10. Such diagram is commonly used in articles to demonstrate the mixing patterns of $\mathrm{Kr}$ and Xe between the two endmembers "Chassigny" (Martian interior component) and the Martian atmosphere. The Martian atmosphere is represented here in Figure 11 by both measurements from Viking [20] and by meteorite data (both from the shergottites and nakhlites). The reason for those two different Martian atmospheric endmembers is however not yet properly understood [47]. Similarly to Figure 10, some meteorite data (e.g., Zagami in the Figure 10), show a shift towards the terrestrial atmosphere component, which can be attributed to contamination by terrestrial air [53]. The two samples of Tissint reported in the plot indicate a mixture between Martian atmosphere and Martian interior components [47].

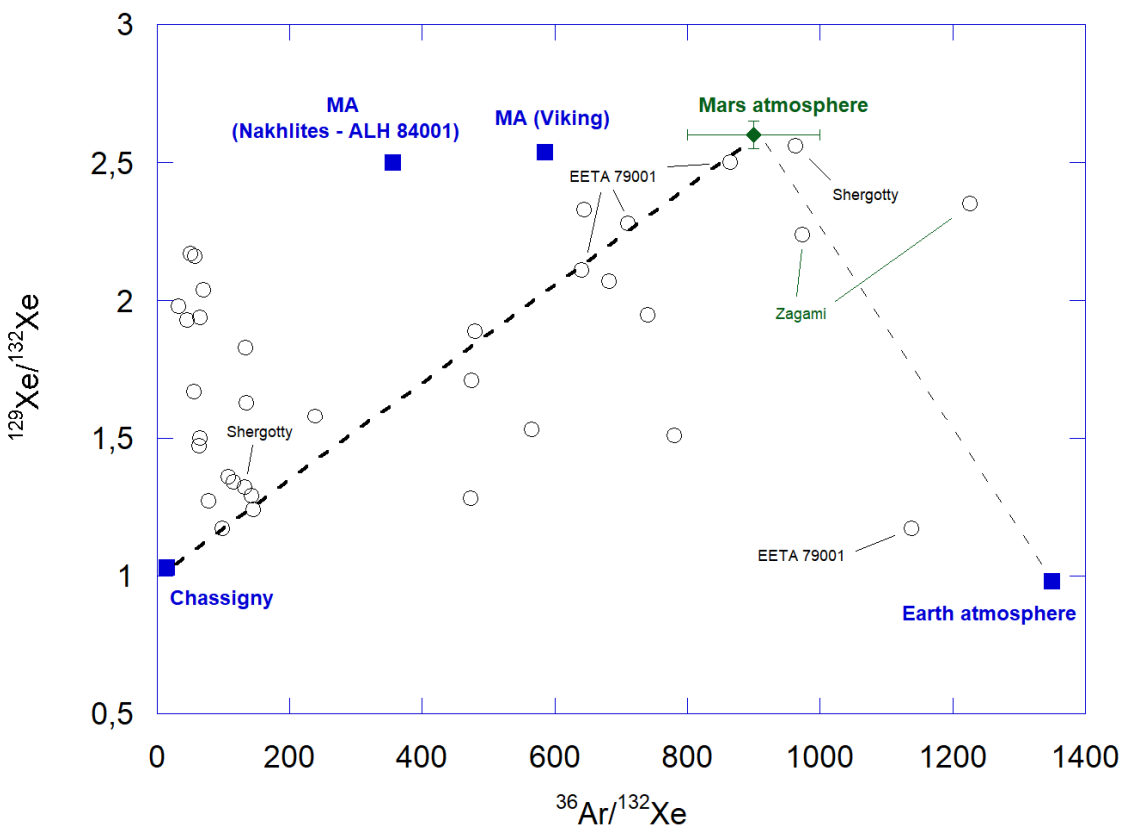

Figure 10. Plot of ${ }^{129} \mathrm{Xe} /{ }^{132} \mathrm{Xe}$ vs. ${ }^{36} \mathrm{Ar} /{ }^{132} \mathrm{Xe}$ in Martian meteorites, data compiled after Bogard and Garrison [94]. Martian atmosphere, based on meteorites (shergottites and nakhlites) and on the Viking data [20] (MA), Martian interior (Chassigny) as well as the Earth atmosphere are indicated. The "Mars Atmosphere" is estimated based on measurements on glass samples by Bogard and Garrison [98] and defined as ${ }^{36} \mathrm{Ar} /{ }^{132} \mathrm{Xe} \sim 900 \pm 100,{ }^{129} \mathrm{Xe} /{ }^{132} \mathrm{Xe} \sim 2.60 \pm 0.05$. Error bars are omitted on meteorite data for clarity. Adapted and modified from Bogard and Garrison [98]. 


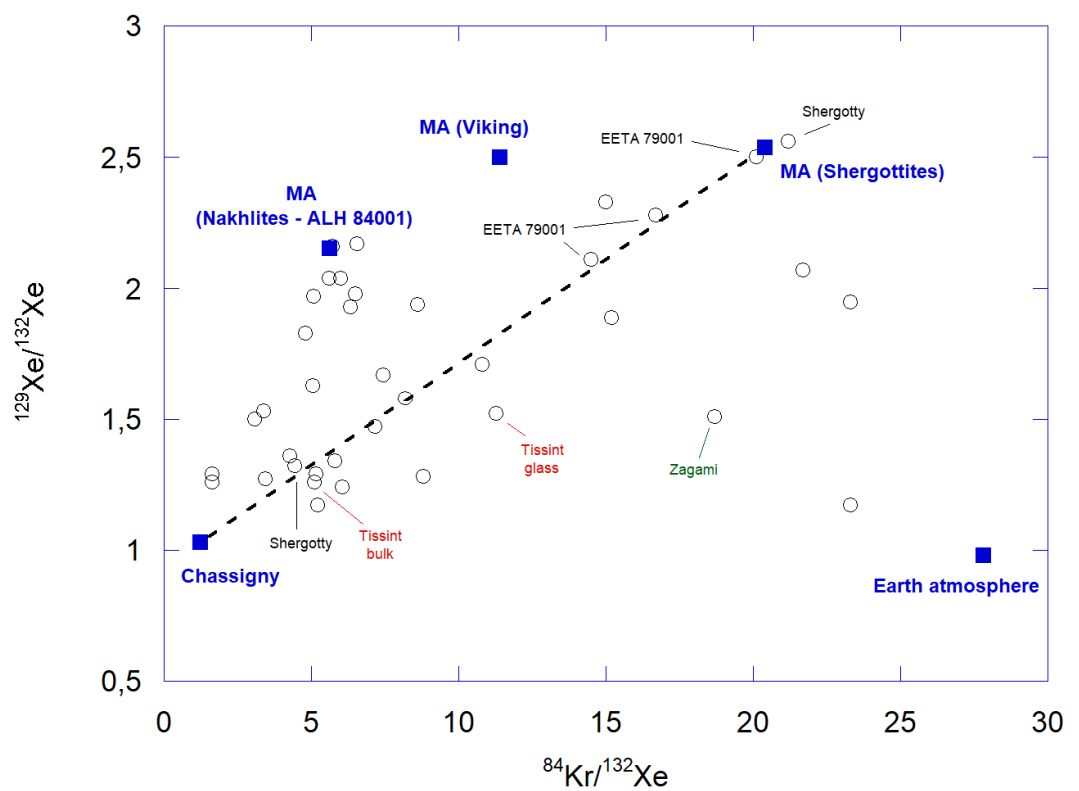

Figure 11. Plot of ${ }^{129} \mathrm{Xe} /{ }^{132} \mathrm{Xe}$ vs. ${ }^{84} \mathrm{Kr} /{ }^{132} \mathrm{Xe}$ in Martian meteorites, data compiled after Bogard and Garrison [98] and [47]. Martian atmosphere based on meteorites (shergottites and nakhlites) and on the Viking data [20] (MA), Martian interior (Chassigny) as well as the Earth atmosphere are indicated. Error bars are omitted for the clarity of the data. Adapted and modified from the work in [47].

\section{Conclusions}

In this review, we have presented the latest in situ and laboratory techniques currently used for the measurement of noble gas isotopic composition at Mars and in Martian meteorites, respectively. The results are a unique set of complementary data which improve our knowledge of atmospheric processes occurring on Mars over geological timescales. Both in situ and laboratory measurements are consistent, demonstrating the Mars-Martian meteorite connection:

(i) $\quad \mathrm{The}^{36} \mathrm{Ar} /{ }^{38} \mathrm{Ar}$ ratio is the lowest measured on any planetary material in the solar system, except in some Martian meteorites, with values ranging from 3.5-4.6 (Figure 3). It is generally lower than the first Viking measurements (i.e., $\left.{ }^{36} \mathrm{Ar} /{ }^{38} \mathrm{Ar} \sim 5.5\right)$. A preferential loss of the lighter isotopes and an enrichment in the heavier have been as well identified for the $\mathrm{D} / \mathrm{H},{ }^{14} \mathrm{~N} /{ }^{15} \mathrm{~N},{ }^{12} \mathrm{C} /{ }^{13} \mathrm{C}$, or ${ }^{16} \mathrm{O} /{ }^{18} \mathrm{O}$ ratios, all in favor of an atmospheric loss during the last $4 \mathrm{Ga}$ [35]. In addition, the significant enrichments in heavy Xe isotopes observed in the Martian atmosphere could be explained by a preferential loss of light Xe isotopes to space by hydrodynamic escape during the Martian early history [33-35];

(ii) SAM onboard Curiosity measured a ${ }^{40} \mathrm{Ar} /{ }^{36} \mathrm{Ar}$ value of $1900 \pm 300$ [40], which is relatively consistent with the ratios measured in Martian meteorites such as EETA $79001\left({ }^{40} \mathrm{Ar} /{ }^{36} \mathrm{Ar}\right.$ $\sim 2050 \pm 70$ [63]) or Tissint $\left({ }^{40} \mathrm{Ar} /{ }^{36} \mathrm{Ar}=1714 \pm 170\right.$ [46]), but not matching the previous measurements by Viking (i.e., ${ }^{40} \mathrm{Ar} /{ }^{36} \mathrm{Ar} \sim 3000 \pm 500$, [20]);

(iii) The xenon spectra show a clear enrichment in ${ }^{129} \mathrm{Xe}$, with, e.g., ${ }^{129} \mathrm{Xe} /{ }^{132} \mathrm{Xe} \sim 2.38-2.52$, both determined by Viking, Curiosity, and in Martian meteorites. Such excesses could be explained by outgassing of radiogenic ${ }^{129} \mathrm{Xe}_{\mathrm{rad}}$. Also, excesses in light Xe isotopes such as ${ }^{124,126} \mathrm{Xe}$ have been detected by SAM, possibly reflecting spallation processes produced by GCRs on Ba and some other REEs;

(iv) Similarly, enrichments in ${ }^{80} \mathrm{Kr}$ can be due to neutron capture on ${ }^{79} \mathrm{Br}$ induced by GCRs.

In a recent review, Grady, 2020 discussed the scientific rationale of returning samples from Mars to laboratories on Earth [99]. The possibility to study samples in the laboratories would lead to answer some of the pending questions such as, e.g., the absolute age of Mars' surface, crust or 
mantle, the characterization of the sedimentary system on Mars, the study of possible deep subsurface environments, the quantification of the In situ Resources Utilization (ISRU), or the establishment of the inventories of the Martian volatiles throughout the geological time scale.

However, in our expectation of samples returned from Mars, Martian meteorites remain the only available, and thus precious, samples for analysis in laboratories. Besides, the study of trapped noble gases in Martian meteorites enables higher precision in the elemental and isotopic ratio measurements compared to spacecraft which have limitations (lower precisions, limitation to measurements of high abundance isotopes, etc.). Whereas some questions have already been answered, such as the Martian atmospheric loss, some others, mainly related to the Martian present-day atmospheric ${ }^{20} \mathrm{Ne} /{ }^{22} \mathrm{Ne}$ ratio or noble gas components, are still not yet properly constrained and demand more analyses in the laboratories.

Author Contributions: Writing-original draft preparation, T.S. and P.M.R.; visualization, T.S. and P.M.R.; supervision, H.H. and R.Z.; funding acquisition, H.H. and R.Z. All authors have read and agreed to the published version of the manuscript.

Funding: This research was funded by the State Key Laboratory of Lithospheric Evolution, IGGCAS, Beijing, through grant numbers SKL-K201801 and SKL-K201802. The work of T. Smith was supported through the Chinese Academy of Sciences "President's International Fellowship Initiative" (PIFI).

Acknowledgments: We thank four anonymous reviewers for the insightful suggestions and valuable comments, which helped to improve the manuscript, and Hitesh Changela and Elias Chatzitheodoridis for the invitation to this review and for language polishing. We also thank K. Sukhanova and W. Guo for fruitful discussions. Finally, the authors thank the Civil Aerospace pre-research project D020302 and the Chinese Academy of Sciences through the project ZDRW-KT-2019-5-5.

Conflicts of Interest: The authors declare no conflict of interest.

\section{References}

1. Ozima, M.; Podosek, F.A. Noble Gas Geochemistry; Cambridge University Press: Cambridge, UK, 2002.

2. Wieler, R. Noble gases in the solar system. Rev. Mineral. Geochem. 2002, 47, 21-70. [CrossRef]

3. Ott, U. Composition of the Martian atmosphere. Space Sci. Rev. 1991, 56, 23-29. [CrossRef]

4. Mahaffy, P.R.; Webster, C.R.; Cabane, M.; Conrad, P.G.; Coll, P.; Atreya, S.K.; Arvey, R.; Barciniak, M.; Benna, M.; Bleacher, L. The sample analysis at Mars investigation and instrument suite. Space Sci. Rev. 2012, 170, 401-478. [CrossRef]

5. Caffee, M.; Hudson, G.; Velsko, C.; Huss, G.; Alexander, E.; Chivas, A. Primordial noble gases from Earth's mantle: Identification of a primitive volatile component. Science 1999, 285, 2115-2118. [CrossRef] [PubMed]

6. Kurz, M.; Jenkins, W. Noble gases and mantle reservoirs: Constraints from isotope ratios, degassing fluxes, and noble gas abundances and ratios. AGU Fall Meet. Abstr. 2005, 2005, V22A-01.

7. Mukhopadhyay, S.; Parai, R. Noble gases: A record of Earth's evolution and mantle dynamics. Annu. Rev. Earth Planet. Sci. 2019, 47, 389-419. [CrossRef]

8. Su, F.; Xiao, Y.; He, H.; Su, B.; Wang, Y.; Zhu, R. He and Ar isotope geochemistry of pyroxene megacrysts and mantle xenoliths in Cenozoic basalt from the Changle-Linqu area in western Shandong. Chin. Sci. Bull. 2014, 59, 396-411. [CrossRef]

9. Swindle, T.D. Martian noble gases. Rev. Mineral. Geochem. 2002, 47, 171-190. [CrossRef]

10. Curran, N.; Nottingham, M.; Alexander, L.; Crawford, I.; Füri, E.; Joy, K. A database of noble gases in lunar samples in preparation for mass spectrometry on the Moon. Planet. Space Sci. 2020, 182, 104823. [CrossRef]

11. Wieler, R.; Heber, V. Noble gas isotopes on the Moon. Space Sci. Rev. 2003, 106, 197-210. [CrossRef]

12. Niemann, H.; Harpold, D.; Atreya, S.; Carignan, G.; Hunten, D.; Owen, T. Galileo probe mass spectrometer experiment. In The Galileo Mission; Springer: Berlin/Heidelberg, Germany, 1992; pp. 111-142.

13. Niemann, H.B.; Atreya, S.K.; Carignan, G.R.; Donahue, T.M.; Haberman, J.A.; Harpold, D.N.; Hartle, R.E.; Hunten, D.M.; Kasprzak, W.T.; Mahaffy, P.R. The Galileo probe mass spectrometer: Composition of Jupiter's atmosphere. Science 1996, 272, 846-849. [CrossRef] [PubMed]

14. Le Roy, L.; Altwegg, K.; Balsiger, H.; Berthelier, J.-J.; Bieler, A.; Briois, C.; Calmonte, U.; Combi, M.R.; De Keyser, J.; Dhooghe, F. Inventory of the volatiles on comet 67P/Churyumov-Gerasimenko from ROSETTA/ROSINA. Astron. Astrophys. 2015, 583, A1. [CrossRef] 
15. Luspay-Kuti, A.; Hässig, M.; Fuselier, S.; Mandt, K.; Altwegg, K.; Balsiger, H.; Gasc, S.; Jäckel, A.; Le Roy, L.; Rubin, M. Composition-dependent outgassing of comet 67P/Churyumov-Gerasimenko from ROSINA/DFMS-implications for nucleus heterogeneity? Astron. Astrophys. 2015, 583, A4. [CrossRef]

16. Mall, U.; Altwegg, K.; Balsiger, H.; Bar-Nun, A.; Berthelier, J.-J.; Bieler, A.; Bochsler, P.; Briois, C.; Calmonte, U.; Combi, M.R. High-time resolution in situ investigation of major cometary volatiles around 67P/C-G at 3.1-2.3 AU measured with Rosina-RTOF. Astrophys. J. 2016, 819, 126. [CrossRef]

17. Marty, B.; Altwegg, K.; Balsiger, H.; Bar-Nun, A.; Bekaert, D.; Berthelier, J.-J.; Bieler, A.; Briois, C.; Calmonte, U.; Combi, M. Xenon isotopes in 67P/Churyumov-Gerasimenko show that comets contributed to earth's atmosphere. Science 2017, 356, 1069-1072. [CrossRef]

18. Owen, T.; Biemann, K. Composition of the atmosphere at the surface of Mars: Detection of argon-36 and preliminary analysis. Science 1976, 193, 801-803. [CrossRef]

19. Owen, T.; Biemann, K.; Rushneck, D.; Biller, J.; Howarth, D.; LaFleur, A. The atmosphere of Mars: Detection of krypton and xenon. Science 1976, 194, 1293-1295. [CrossRef]

20. Owen, T.; Biemann, K.; Rushneck, D.; Biller, J.; Howarth, D.; Lafleur, A. The composition of the atmosphere at the surface of Mars. J. Geophys. Res. 1977, 82, 4635-4639. [CrossRef]

21. Mousis, O.; Atkinson, D.H.; Cavalié, T.; Fletcher, L.; Amato, M.; Aslam, S.; Ferri, F.; Renard, J.B.; Spilker, T.; Venkatapathy, E. Scientific rationale for Uranus and Neptune in situ explorations. Planet. Space Sci. 2018, 155, 12-40. [CrossRef]

22. Pepin, R. Meteorites: Evidence of Martian origins. Nature 1985, 317, 473-474. [CrossRef]

23. Becker, R.; Pepin, R. The case for a martian origin of the shergottites: Nitrogen and noble gases in EETA 79001. Earth Planet. Sci. Lett. 1984, 69, 225-242. [CrossRef]

24. Bogard, D.D.; Johnson, P. Martian gases in an Antarctic meteorite? Science 1983, 221, 651-654. [CrossRef]

25. Irving, A.J. Martian Meteorites. Available online: https://imca.cc/mars/martian-meteorites.htm (accessed on 10 September 2020).

26. McSween, H.Y., Jr. What we have learned about Mars from SNC meteorites. Meteoritics 1994, 29, 757-779. [CrossRef]

27. Ott, U. Noble gases in SNC meteorites: Shergotty, Nakhla, Chassigny. Geochim. Cosmochim. Acta 1988, 52, 1937-1948. [CrossRef]

28. McSween, H.Y., Jr. Petrology on Mars. Am. Mineral. 2015, 100, 2380-2395. [CrossRef]

29. Marti, K.; Kim, J.; Thakur, A.; McCoy, T.J.; Keil, K. Signatures of the Martian atmosphere in glass of the Zagami meteorite. Science 1995, 267, 1981-1984. [CrossRef]

30. Odert, P.; Lammer, H.; Erkaev, N.V.; Nikolaou, A.; Lichtenegger, H.I.; Johnstone, C.P.; Kislyakova, K.G.; Leitzinger, M.; Tosi, N. Escape and fractionation of volatiles and noble gases from Mars-sized planetary embryos and growing protoplanets. Icarus 2018, 307, 327-346. [CrossRef]

31. Atreya, S.K.; Trainer, M.G.; Franz, H.B.; Wong, M.H.; Manning, H.L.; Malespin, C.A.; Mahaffy, P.R.; Conrad, P.G.; Brunner, A.E.; Leshin, L.A. Primordial argon isotope fractionation in the atmosphere of Mars measured by the SAM instrument on Curiosity and implications for atmospheric loss. Geophys. Res. Lett. 2013, 40, 5605-5609. [CrossRef]

32. Jakosky, B.M.; Slipski, M.; Benna, M.; Mahaffy, P.; Elrod, M.; Yelle, R.; Stone, S.; Alsaeed, N. Mars' atmospheric history derived from upper-atmosphere measurements of ${ }^{38} \mathrm{Ar} /{ }^{36} \mathrm{Ar}$. Science 2017, 355, 1408-1410. [CrossRef]

33. Cassata, W.S. Meteorite constraints on Martian atmospheric loss and paleoclimate. Earth Planet. Sci. Lett. 2017, 479, 322-329. [CrossRef]

34. Luhmann, J.; Johnson, R.; Zhang, M. Evolutionary impact of sputtering of the Martian atmosphere by $\mathrm{O}^{+}$ pickup ions. Geophys. Res. Lett. 1992, 19, 2151-2154. [CrossRef]

35. Pepin, R.O. On the origin and early evolution of terrestrial planet atmospheres and meteoritic volatiles. Icarus 1991, 92, 2-79. [CrossRef]

36. Koike, M.; Sumino, H.; Sano, Y.; Ozima, M. Combined stepwise heating and vacuum crushing analyses of noble gases in shergottites. In Proceedings of the Lunar and Planetary Science Conference, Woodlands, TX, USA, 20-24 March 2017.

37. Park, J.; Nagao, K. New insights on Martian atmospheric neon from Martian meteorite, Dhofar 378. In Proceedings of the 37th Lunar and Planetary Science Conference, Woodlands, TX, USA, 14-18 March 2006. 
38. Park, J.; Nyquist, L.; Herzog, G.; Nagao, K.; Mikouchi, T.; Kusakabe, M. ${ }^{20} \mathrm{Ne} /{ }^{22} \mathrm{Ne}$ in the Martian atmosphere: New evidence from Martian meteorites. In Proceedings of the Lunar and Planetary Science Conference, Woodlands, TX, USA, 20-24 March 2017.

39. Wiens, R.; Becker, R.; Pepin, R. The case for a Martian origin of the Shergottites, ii. Trapped and indigenous gas components in EETA 79001 glass. Earth Planet. Sci. Lett. 1986, 77, 149-158. [CrossRef]

40. Mahaffy, P.R.; Webster, C.R.; Atreya, S.K.; Franz, H.; Wong, M.; Conrad, P.G.; Harpold, D.; Jones, J.J.; Leshin, L.A.; Manning, H. Abundance and isotopic composition of gases in the Martian atmosphere from the Curiosity rover. Science 2013, 341, 263-266. [CrossRef]

41. Conrad, P.G.; Malespin, C.A.; Franz, H.B.; Pepin, R.O.; Trainer, M.G.; Schwenzer, S.P.; Atreya, S.; Freissinet, C.; Jones, J.; Manning, H. In situ measurement of atmospheric krypton and xenon on Mars with Mars Science Laboratory. Earth Planet. Sci. Lett. 2016, 454,1-9. [CrossRef]

42. Mahaffy, P.R.; Benna, M.; King, T.; Harpold, D.N.; Arvey, R.; Barciniak, M.; Bendt, M.; Carrigan, D.; Errigo, T.; Holmes, V. The neutral gas and ion mass spectrometer on the Mars atmosphere and volatile evolution mission. Space Sci. Rev. 2015, 195, 49-73. [CrossRef]

43. Bhardwaj, A.; Mohankumar, S.; Das, T.P.; Pradeepkumar, P.; Sreelatha, P.; Sundar, B.; Nandi, A.; Vajja, D.P.; Dhanya, M.; Naik, N. MENCA experiment aboard India's Mars orbiter mission. Curr. Sci. 2015, 109, 1106-1113. [CrossRef]

44. Bhardwaj, A.; Thampi, S.V.; Das, T.P.; Dhanya, M.; Naik, N.; Vajja, D.P.; Pradeepkumar, P.; Sreelatha, P.; Thampi, R.S.; Yadav, V.K. Observation of suprathermal argon in the exosphere of Mars. Geophys. Res. Lett. 2017, 44, 2088-2095. [CrossRef]

45. Wieler, R. Noble gas mass spectrometry. In Treatise on Geochemistry; Elsevier: Amsterdam, The Netherlands, 2014; Volume 15, pp. 355-373.

46. Avice, G.; Bekaert, D.; Chennaoui Aoudjehane, H.; Marty, B. Noble gases and nitrogen in Tissint reveal the composition of the Mars atmosphere. Geochem. Perspect. Lett. 2018, 6, 11-16. [CrossRef]

47. Wieler, R.; Huber, L.; Busemann, H.; Seiler, S.; Leya, I.; Maden, C.; Masarik, J.; Meier, M.; Nagao, K.; Trappitsch, R. Noble gases in 18 Martian meteorites and Angrite Northwest Africa 7812-Exposure ages, trapped gases, and a re-evaluation of the evidence for solar cosmic ray-produced neon in shergottites and other achondrites. Meteorit. Planet. Sci. 2016, 51, 407-428. [CrossRef]

48. He, H.; Zhu, R.; Saxton, J. Noble gas isotopes in corundum and peridotite xenoliths from the eastern north China craton: Implication for comprehensive refertilization of lithospheric mantle. Phys. Earth Planet. Inter. 2011, 189, 185-191. [CrossRef]

49. Ranjith, P.; He, H.; Miao, B.; Su, F.; Zhang, C.; Xia, Z.; Xie, L.; Zhu, R. Petrographic shock indicators and noble gas signatures in a $\mathrm{H}$ and an L chondrite from Antarctica. Planet. Space Sci. 2017, 146, 20-29. [CrossRef]

50. Frick, U.; Pepin, R. On the distribution of noble gases in Allende: A differential oxidation study. Earth Planet. Sci. Lett. 1981, 56, 45-63. [CrossRef]

51. Wiens, R. Noble gases released by vacuum crushing of EETA 79001 glass. Earth Planet. Sci. Lett. 1988, 91, 55-65. [CrossRef]

52. Blard, P.H.; Puchol, N.; Farley, K. Constraints on the loss of matrix-sited helium during vacuum crushing of mafic phenocrysts. Geochim. Cosmochim. Acta 2008, 72, 3788-3803. [CrossRef]

53. Ott, U.; Swindle, T.D.; Schwenzer, S.P. Noble gases in Martian meteorites: Budget, sources, sinks, and processes. In Volatiles in the Martian Crust; Elsevier: Amsterdam, The Netherlands, 2019; pp. 35-70.

54. Guo, W.; He, H.; Hilton, D.R.; Zheng, Y.; Su, F.; Liu, Y.; Zhu, R. Recycled noble gases preserved in podiform chromitites from Luobusa, Tibet. Chem. Geol. 2017, 469, 97-109. [CrossRef]

55. Riebe, M.E.; Welten, K.C.; Meier, M.M.; Wieler, R.; Barth, M.; Ward, D.; Laubenstein, M.; Bischoff, A.; Caffee, M.W.; Nishiizumi, K. Cosmic-ray exposure ages of six chondritic Almahata Sitta fragments. Meteorit. Planet. Sci. 2017, 52, 2353-2374. [CrossRef]

56. Lott, D.E., III. Improvements in noble gas separation methodology: A nude cryogenic trap. Geochem. Geophys. Geosyst. 2001, 2. [CrossRef]

57. Mahajan, R.R. Exposure ages, noble gases and nitrogen in the ordinary chondrite Karimati (L5). Earth Moon Planets 2020, 124, 3-13. [CrossRef]

58. Mahajan, R.R. Noble gases and nitrogen in metal from the ordinary chondrites Katol (L6), Itawa Bhopji (L3-5) and Portales Valley (H6). Astrophys. Space Sci. 2020, 365, 130. [CrossRef] 
59. Mohapatra, R.K.; Schwenzer, S.P.; Herrmann, S.; Murty, S.; Ott, U.; Gilmour, J.D. Noble gases and nitrogen in Martian meteorites Dar Al Gani 476, Sayh Al Uhaymir 005 and Lewis Cliff 88516: EFA and extra neon. Geochim. Cosmochim. Acta 2009, 73, 1505-1522. [CrossRef]

60. Heber, V.S.; Wieler, R.; Baur, H.; Olinger, C.; Friedmann, T.A.; Burnett, D.S. Noble gas composition of the solar wind as collected by the Genesis mission. Geochim. Cosmochim. Acta 2009, 73, 7414-7432. [CrossRef]

61. Garrison, D.H.; Bogard, D.D. Isotopic composition of trapped and cosmogenic noble gases in several Martian meteorites. Meteorit. Planet. Sci. 1998, 33, 721-736. [CrossRef]

62. Bogard, D.D. A reappraisal of the Martian ${ }^{36} \mathrm{Ar} /{ }^{38} \mathrm{Ar}$ ratio. J. Geophys. Res. Planets 1997, 102, $1653-1661$. [CrossRef]

63. Bogard, D.; Clayton, R.; Marti, K.; Owen, T.; Turner, G. Martian volatiles: Isotopic composition, origin, and evolution. In Chronology and Evolution of Mars; Springer: Berlin/Heidelberg, Germany, 2001; pp. 425-458.

64. Mathew, K.; Marti, K. Early evolution of Martian volatiles: Nitrogen and noble gas components in ALH 84001 and Chassigny. J. Geophys. Res. Planets 2001, 106, 1401-1422. [CrossRef]

65. Owen, T. The composition and early history of the atmosphere of Mars. In Mars; University of Arizona Press: Tucson, AZ, USA, 1992; pp. 818-834.

66. Nakamura, M.; Yamashita, K.; Yoshikawa, I.; Shiomi, K.; Yamazaki, A.; Sasaki, S.; Takizawa, Y.; Hirahara, M.; Miyake, W.; Saito, Y. Helium observation in the Martian ionosphere by an X-ray ultraviolet scanner on Mars orbiter Nozomi. Earth Planets Space 1999, 51, 61-70. [CrossRef]

67. Krasnopolsky, V.; Bowyer, S.; Chakrabarti, S.; Gladstone, G.; McDonald, J. First measurement of helium on Mars: Implications for the problem of radiogenic gases on the terrestrial planets. Icarus 1994, 109, 337-351. [CrossRef] [PubMed]

68. Krasnopolsky, V.A.; Gladstone, G.R. Helium on Mars and Venus: EUVE observations and modeling. Icarus 2005, 176, 395-407. [CrossRef]

69. Brennecka, G.; Borg, L.; Wadhwa, M. Insights into the Martian mantle: The age and isotopics of the meteorite fall Tissint. Meteorit. Planet. Sci. 2014, 49, 412-418. [CrossRef]

70. Nishiizumi, K.; Nagao, K.; Caffee, M.; Jull, A.; Irving, A. Cosmic-ray exposure chronologies of depleted olivine-phyric shergottites. In Proceedings of the 42nd Lunar and Planetary Science Conference, Woodlands, TX, USA, 7-11 March 2011; p. 2371.

71. Povinec, P.; Koeberl, C.; Jull, A.; Sýkora, I.; Ferrière, L.; Kovácik, A. Radionuclides in the Tissint meteorite: Implications for its martian origin. In Proceedings of the Lunar and Planetary Science Conference, Woodlands, TX, USA, 18-22 March 2019.

72. Busemann, H.; Baur, H.; Wieler, R. Primordial noble gases in "phase Q" in carbonaceous and ordinary chondrites studied by closed-system stepped etching. Meteorit. Planet. Sci. 2000, 35, 949-973. [CrossRef]

73. Schultz, L.; Franke, L. Helium, neon, and argon in meteorites: A data collection. Meteorit. Planet. Sci. 2004, 39, 1889-1890. [CrossRef]

74. Llorca, J.; Roszjar, J.; Cartwright, J.A.; Bischoff, A.; Ott, U.; Pack, A.; Merchel, S.; Rugel, G.; Fimiani, L.; Ludwig, P.; et al. The Ksar Ghilane 002 shergottite-the 100th registered Martian fragment. Meteorit. Planet. Sci. 2013, 48, 493-513. [CrossRef]

75. Murty, S.; Mahajan, R.; Das, J.; Sinha, N.; Goswami, J.J.P.R. Trapped and cosmogenic gas components and nuclear tracks in the Nakhlite Y000593. In Proceedings of the International Symposium, Evolution of Solar System Materials: A New Perspective from Antarctic Meteorites. National Institute of Polar Research, Tokyo, Japan, 3-5 September 2003; pp. 90-91.

76. Schwenzer, S.P.; Herrmann, S.; Ott, U. Noble gases in two shergottites and one nakhlite from Antarctica: Y00027, Y00097, and Y000593. Polar Sci. 2009, 3, 83-99. [CrossRef]

77. Cartwright, J.; Ott, U.; Herrmann, S.; Agee, C. Modern atmospheric signatures in 4.4 Ga Martian meteorite NWA 7034. Earth Planet. Sci. Lett. 2014, 400,77-87. [CrossRef]

78. Matsubara, K.; Matsuda, J. Anomalous Ne enrichments in tektites. Meteoritics 1991, 26, 217-220. [CrossRef]

79. Jakosky, B.M.; Pepin, R.O.; Johnson, R.E.; Fox, J.L. Mars atmospheric loss and isotopic fractionation by solar-wind-induced sputtering and photochemical escape. Icarus 1994, 111, 271-288. [CrossRef]

80. Lee, J.Y.; Marti, K.; Severinghaus, J.P.; Kawamura, K.; Yoo, H.-S.; Lee, J.B.; Kim, J.S. A redetermination of the isotopic abundances of atmospheric Ar. Geochim. Cosmochim. Acta 2006, 70, 4507-4512. [CrossRef] 
81. Mahaffy, P.; Niemann, H.; Alpert, A.; Atreya, S.; Demick, J.; Donahue, T.; Harpold, D.; Owen, T. Noble gas abundance and isotope ratios in the atmosphere of Jupiter from the Galileo probe mass spectrometer. J. Geophys. Res. Planets 2000, 105, 15061-15071. [CrossRef]

82. Pepin, R.O.; Schlutter, D.J.; Becker, R.H.; Reisenfeld, D.B. Helium, neon, and argon composition of the solar wind as recorded in gold and other Genesis collector materials. Geochim. Cosmochim. Acta 2012, 89, 62-80. [CrossRef]

83. Garrison, D.; Hamlin, S.; Bogard, D. Chlorine abundances in meteorites. Meteorit. Planet. Sci. 2000, 35, 419-429. [CrossRef]

84. Wong, M.H.; Atreya, S.K.; Mahaffy, P.N.; Franz, H.B.; Malespin, C.; Trainer, M.G.; Stern, J.C.; Conrad, P.G.; Manning, H.L.; Pepin, R.O. Isotopes of nitrogen on Mars: Atmospheric measurements by Curiosity's mass spectrometer. Geophys. Res. Lett. 2013, 40, 6033-6037. [CrossRef]

85. Murty, S.; Mohapatra, R. Nitrogen and heavy noble gases in ALH 84001: Signatures of ancient Martian atmosphere. Geochim. Cosmochim. Acta 1997, 61, 5417-5428. [CrossRef]

86. Cassata, W.S.; Shuster, D.L.; Renne, P.R.; Weiss, B.P. Trapped Ar isotopes in meteorite ALH 84001 indicate Mars did not have a thick ancient atmosphere. Icarus 2012, 221, 461-465. [CrossRef]

87. Rao, M.N.; Bogard, D.D.; Nyquist, L.E.; McKay, S.D.; Masarik, J. Neutron capture isotopes in the Martian regolith and implications for Martian atmospheric noble gases. Icarus 2002, 156, 353-372. [CrossRef]

88. Mazor, E.; Heymann, D.; Anders, E. Noble gases in carbonaceous chondrites. Geochim. Cosmochim. Acta 1970, 34, 781-824. [CrossRef]

89. Cartwright, J. Noble Gas Components in Martian Meteorites. Ph.D. Thesis, The University of Manchester, Manchester, UK, 2010.

90. Swindle, T.; Caffee, M.; Hohenberg, C.J.G. Xenon and other noble gases in Shergottites. Geochim. Cosmochim. Acta 1986, 50, 1001-1015. [CrossRef]

91. Avice, G.; Marty, B. Perspectives on atmospheric evolution from noble gas and nitrogen isotopes on Earth, Mars \& Venus. Space Sci. Rev. 2020, 216, 36. [CrossRef]

92. Bekaert, D.V.; Broadley, M.W.; Marty, B. The origin and fate of volatile elements on Earth revisited in light of noble gas data obtained from comet 67P/Churyumov-Gerasimenko. Sci. Rep. 2020, 10, 5796. [CrossRef]

93. Yokochi, R.; Marty, B. A determination of the neon isotopic composition of the deep mantle. Earth Planet. Sci. Lett. 2004, 225, 77-88. [CrossRef]

94. Broadley, M.W.; Barry, P.H.; Bekaert, D.V.; Byrne, D.J.; Caracausi, A.; Ballentine, C.J.; Marty, B. Indentification of chondritic krypton and xenon in Yellowstone gases and the timing of terrestrial volatile accretion. Proc. Natl. Acad. Sci. USA 2020, 117, 13997-14004. [CrossRef]

95. Holland, G.; Cassidy, M.; Ballentine, C.J. Meteorite Kr in Earth's mantle suggests a late accretionary source for the atmosphere. Science 2009, 326, 1522-1525. [CrossRef]

96. Pepin, R.O. On the Isotopic Composition of Primordial Xenon in Terrestrial Planet Atmospheres. Space Sci. Rev. 2000, 92, 371-395. [CrossRef]

97. Gilmour, J.; Whitby, J.; Turner, G. Xenon isotopes in irradiated ALH84001: Evidence for shock-induced trapping of ancient Martian atmosphere. Geochim. Cosmochim. Acta 1998, 62, 2555-2571. [CrossRef]

98. Bogard, D.D.; Garrison, D.H. Relative abundances of argon, krypton, and xenon in the Martian atmosphere as measured in Martian meteorites. Geochim. Cosmochim. Acta 1998, 62, 1829-1835. [CrossRef]

99. Grady, M.M. Exploring Mars with returned samples. Space Sci. Rev. 2020, 216, 51. [CrossRef]

Publisher's Note: MDPI stays neutral with regard to jurisdictional claims in published maps and institutional affiliations.

(C) 2020 by the authors. Licensee MDPI, Basel, Switzerland. This article is an open access article distributed under the terms and conditions of the Creative Commons Attribution (CC BY) license (http://creativecommons.org/licenses/by/4.0/). 